\title{
Investigating the effect of gender on the neutralization of client audit management and Auditor Earning Management Discovering Capability
}

\author{
Shokrollah Khajavi* \\ Professor of accounting, Shiraz university (Corresponding Author), \\ shkhajavi@rose.shirazu.ac.ir \\ Farshid Ahmadi Farsani \\ PhD student of Shiraz university, Instructor of Payame Noor University, \\ ahmadi.farshid2@gmail.com
}

\begin{abstract}
Gender has a significant impact on the way information is collected and processed. Also, information processing methods are different in women than men. The goal of this research is to study gender effect on client auditing management neutralizing and auditor earning management discovering capability. Auditing management happens only when client intends to distract auditing focus on other sections (sections which have been manipulated by earning management or fraud) by the means of deviations tactics and wackiness. The statistical research population consists of head supervisor of the auditing organization during summer of 2018, which scenarios were distributed among 120 of them in a quasi-experimental manner. Available sampling has been executed in this research. In order to gender study control in auditing management t-student and Analysis of variance tests were utilized. Research results show that gender differences have positive significant effect on influences of auditing management neutralizing and earning management discovering by auditors in a way which female auditors show better performance in discovering earning management and neutralizing the auditing management effects, whereby the findings can play an important role in the manner of determining the auditing team members, and paying them properly.
\end{abstract}

Keywords: Auditor Gender, Auditing Management, Earning Management.

Copyrights:

This license only allowing others to download your works and share them with others as long as they credit you, but they can't change them in any way or use them commercial. 
dor: 20.1001.1.24767166.1400.6.11.11.4

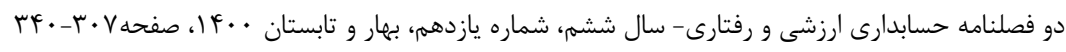

\section{بررسى تاثير جنسيت برخنثى نمودن مديريت حسابرسى صاحبكار وكشف مديريت سود توسط حسابر سان

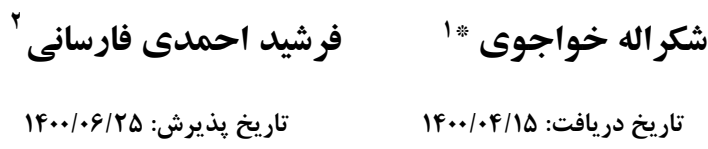

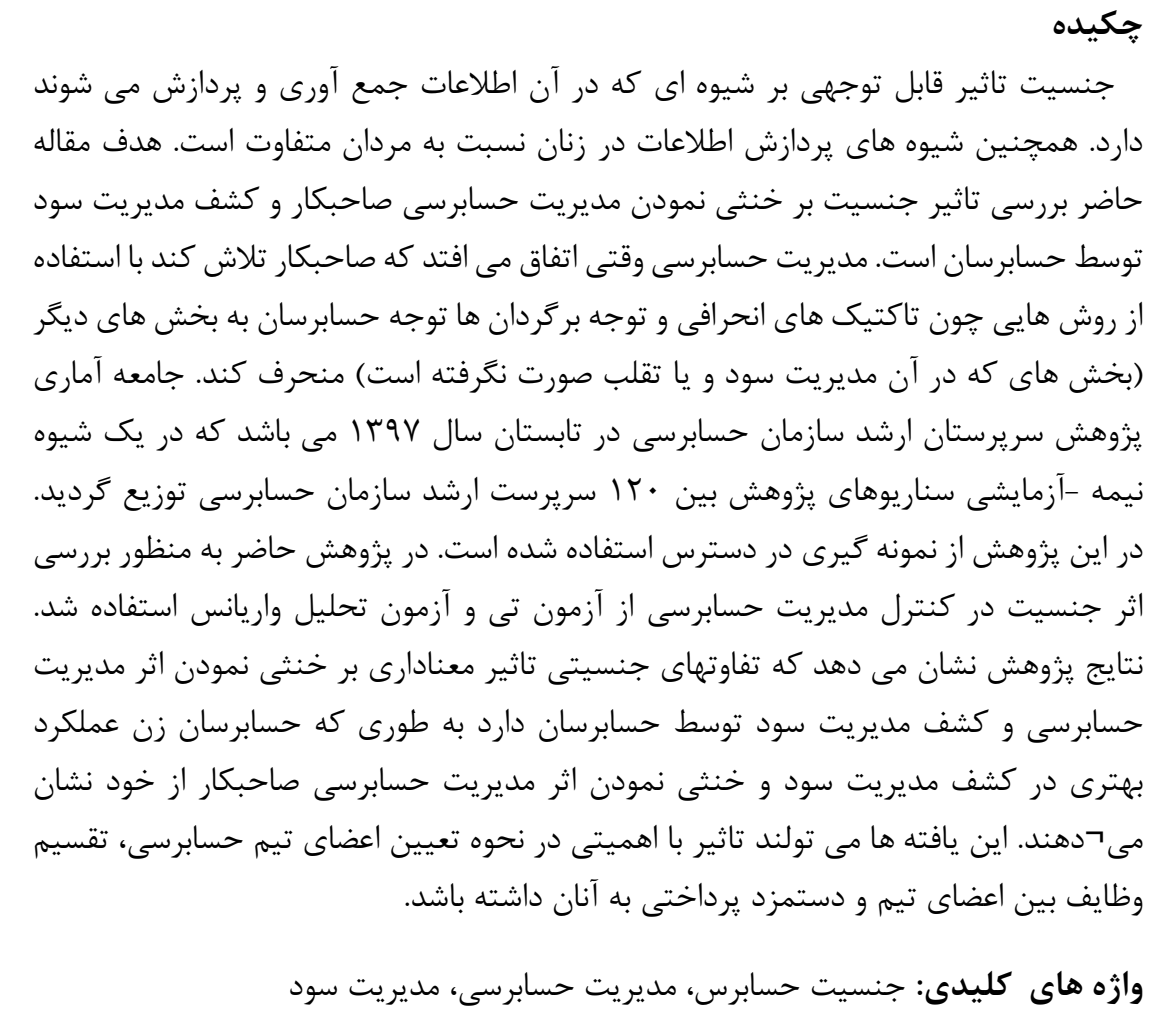

'استاد حسابدارى دانشگاه شيراز (نويسنده مسئول) ، shkhajavi@gmail.com

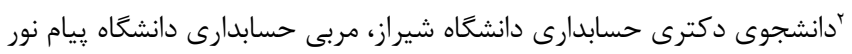

ahmadi.farshid2@gmail.com 
ב

| 1-مقدمه

يكى از عوامل افزايش قابليت اتكاى صورتهاى مالى، كيفيت حسابرسى است. كيفيت حسابرسى

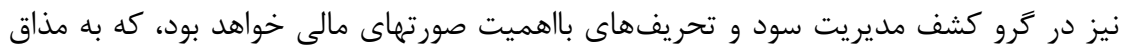

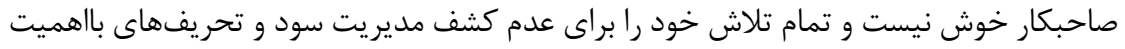

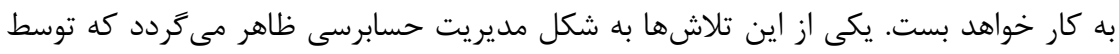

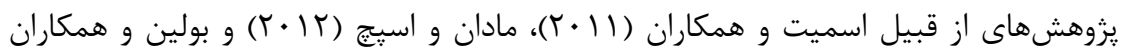

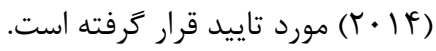

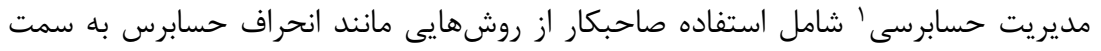

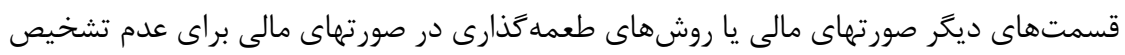

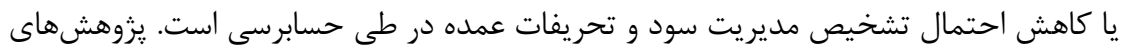

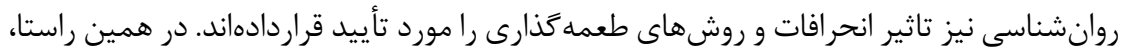

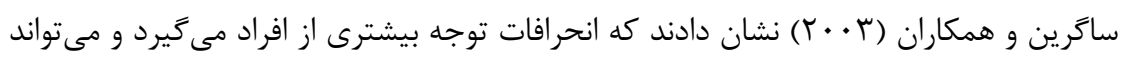

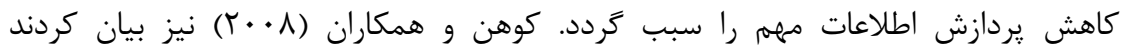

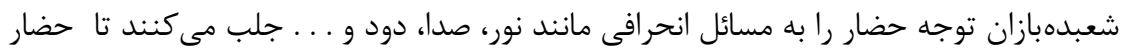

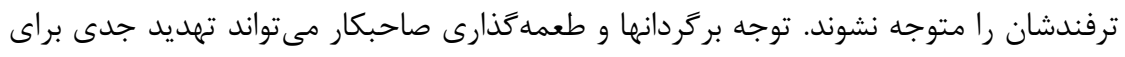

$$
\text { كيفيت حسابرسى محسوب تردد. }
$$

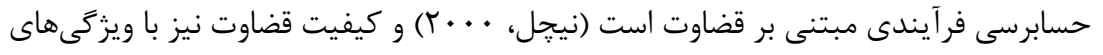

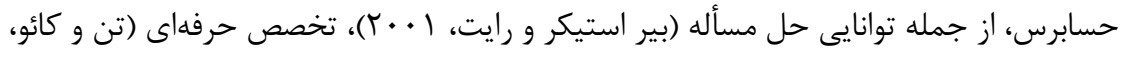

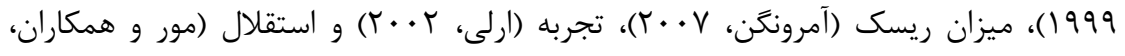

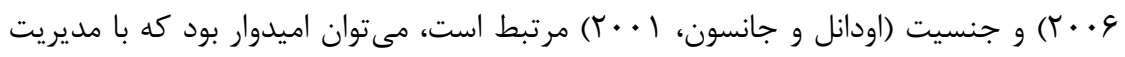

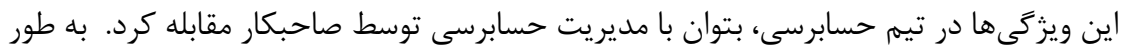

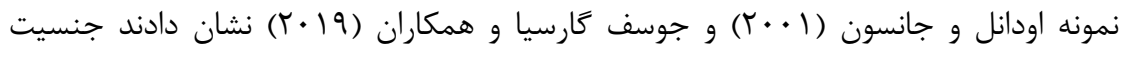

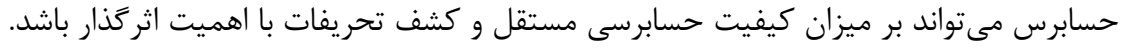

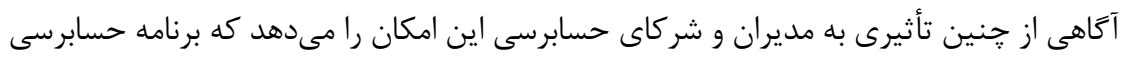

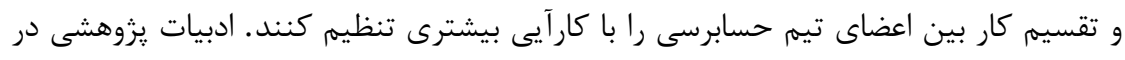

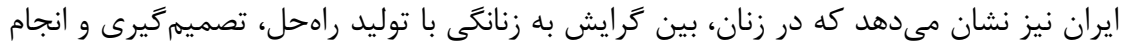

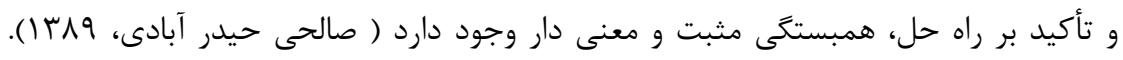

\footnotetext{
${ }^{1}$ Auditing Management
} 


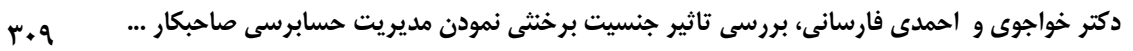

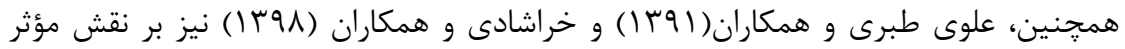
حسابرس زن بر كيفيت حسابرسى تأكيد نمودند.

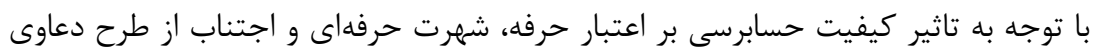
قضايى عليه حسابرسان، حسابرسان بايد هر كونه تحريف با اهميتى را كشف و كزارش كنيند. از

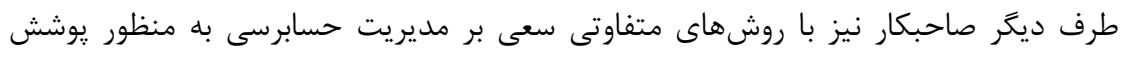
تحريفهاى خود در صورتهاى مالى و عدم كشف آنها توسط حسابرسان را دارئ دارد. بنابراين حسابرسان بايد تمام تلاش خود را در كشف تحريفات صورتهاى مالى انجام دهند. با توجه به

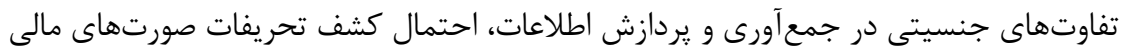

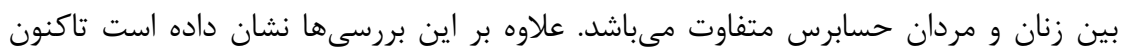
تحقيقى در زمينه جنسيت و مديريت حسابرسى صاحبكار در ايران انجام نشده است. يافتههاى

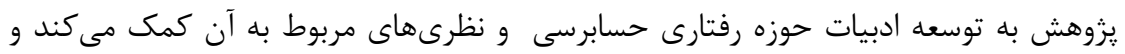

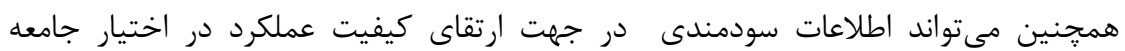

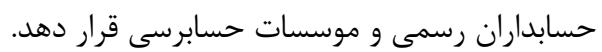

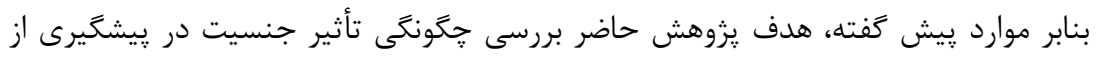

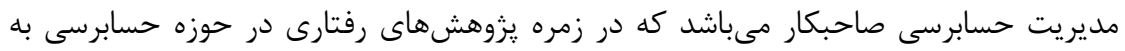

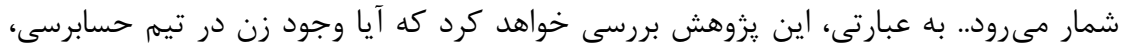
مى تواند به كشف مديريت سود كمك كرده و تلاشهاش

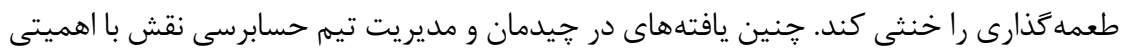

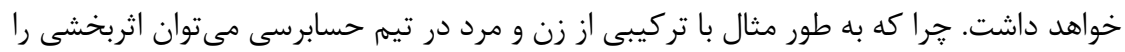
افزايش داده و بر كيفيت حسابرسى افزود.

\section{r- مبانى نظرى و بيشينه يزوهش}

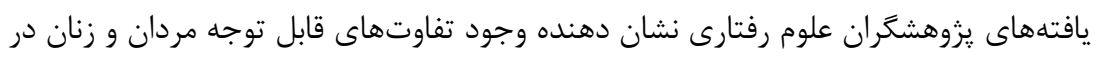

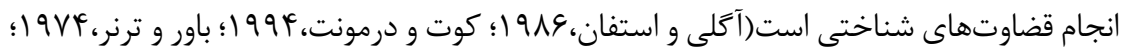

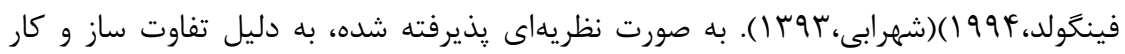

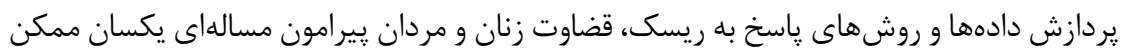

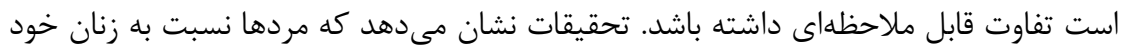

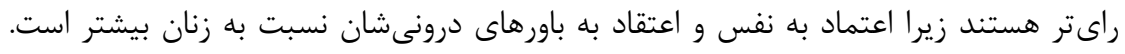

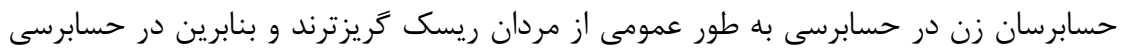

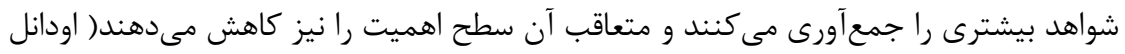


و جانسون، ( • (Y). همجنين شواهد نشان مى دهد كه هنجارها و عقايد ميان مردان و زنان متفاوت

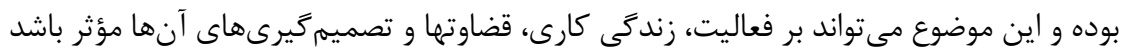

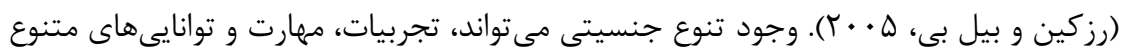

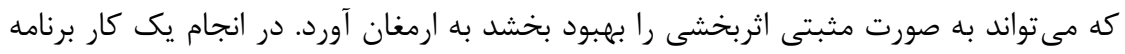

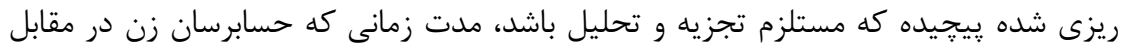

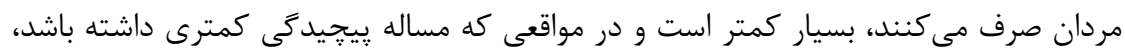

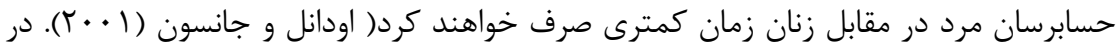

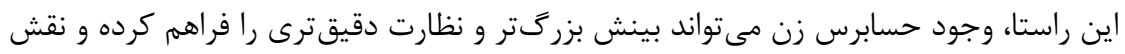
فعال ترى در تيم حسابرسى ايفا كند.

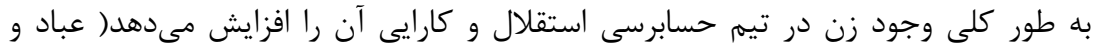

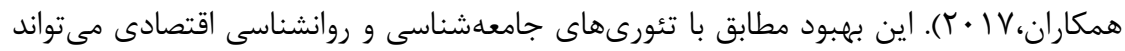

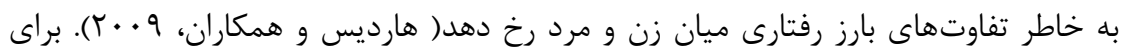
مثال، زنان در مقايسه با مردان، ريسك

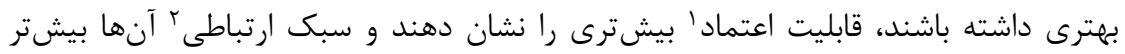

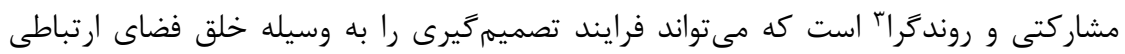

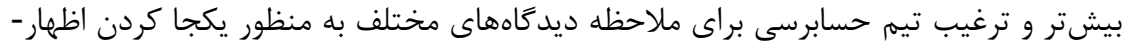

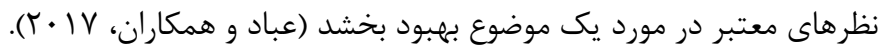

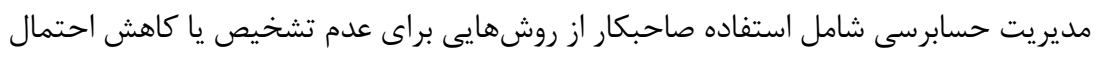
تشخيص مديريت سود در طى حسابرسى است. مديريت حسابرسى روشهاى متعددى را را شامل

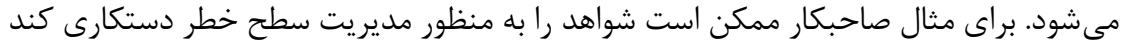

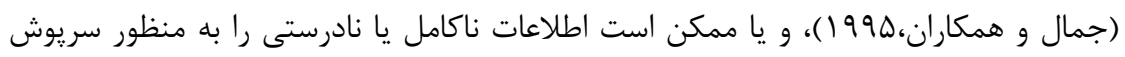

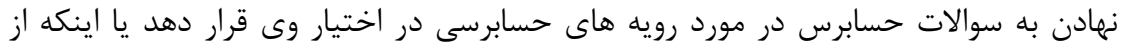

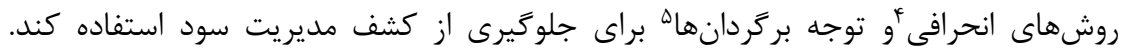

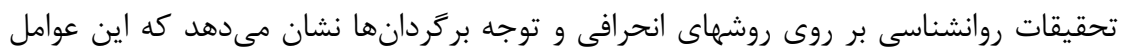

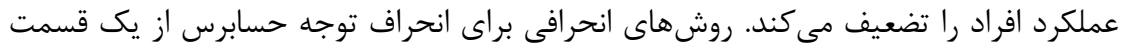

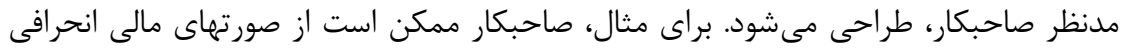

${ }^{1}$ Trustworthiness

${ }^{2}$ Communication

${ }^{3}$ Process-Oriented

${ }^{4}$ Diversions

${ }^{5}$ Distractions 
(حسابهاى تحريف شده) استفاده نمايد تا ريسك را در قسمت هايى كه مديريت سود اتفاق

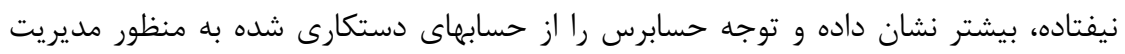

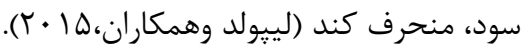

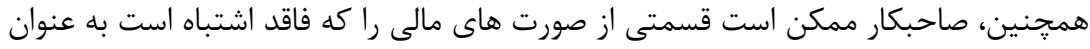

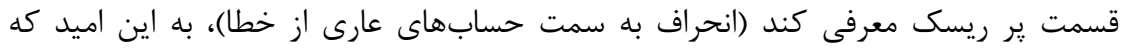

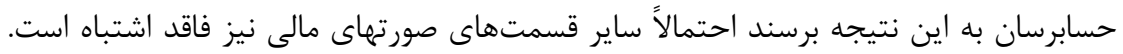

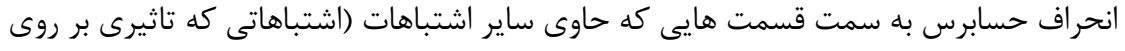

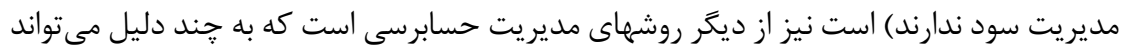

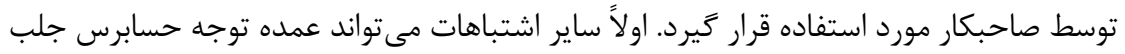

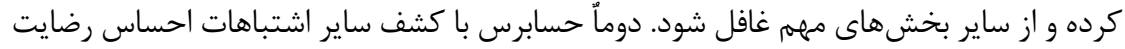

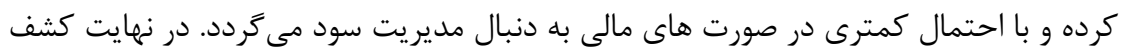

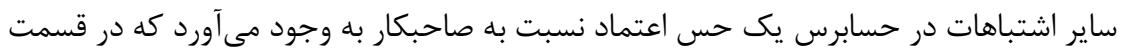
هاى ديخر صورتهاى مالى جستجوى كمترى كند و كفتههاى صاحبكار را بيذيرد (ليبولد و

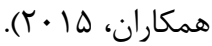
از طرف ديكر انحراف حسابرس به سمت ساير اشتباهات ممكن است اثر معكوس داشته باشد.

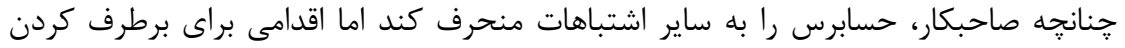

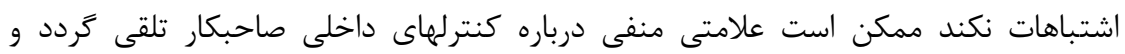

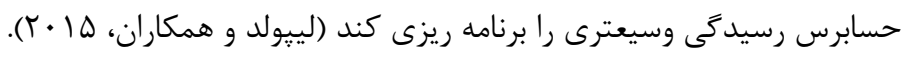

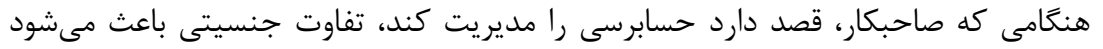

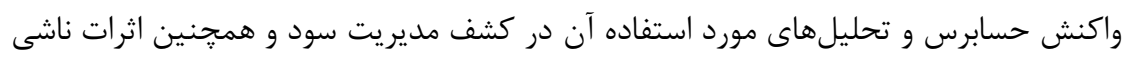

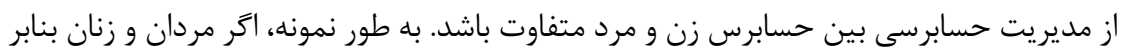

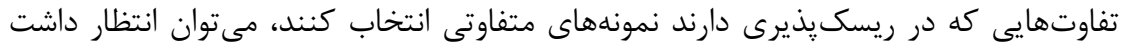

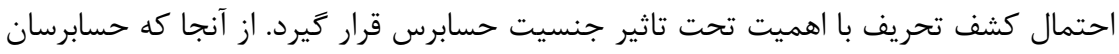

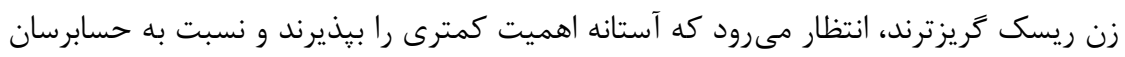

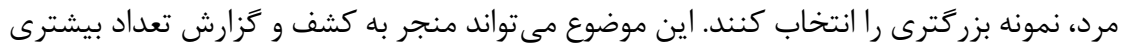

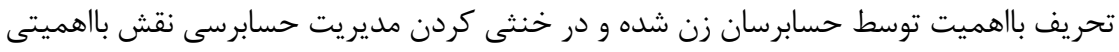

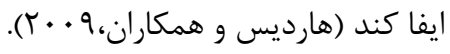


ييشينه يزوهش هاى خارجى

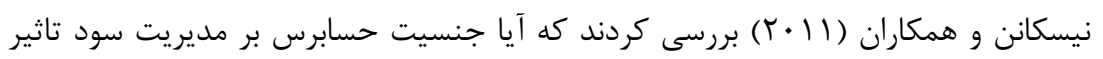

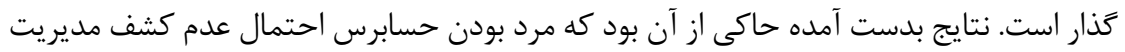

سود را افزايش مى دهد.

اسميت و همكاران (11) (T) نشان دادند حسابرسان توسط شواهد حسابرسى كه در نتيجه

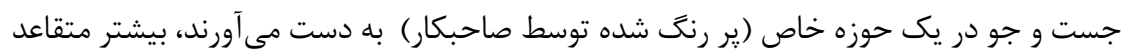

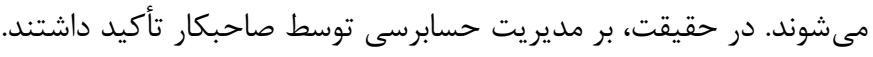

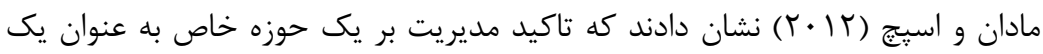

حوزه ير ريسك، منجر مىشود كه حسابرسان فكر كنند اشتباهى وجود ندارد.

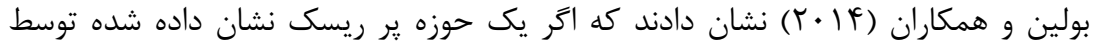

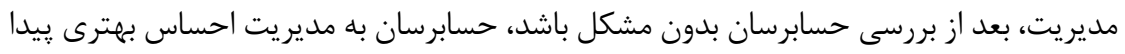

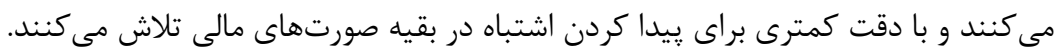

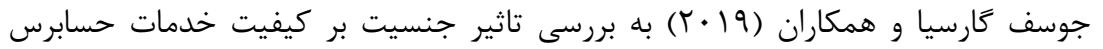

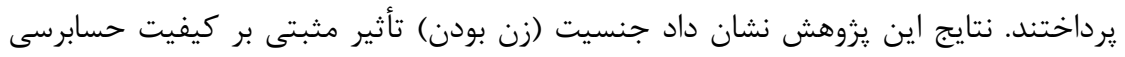
دارد.

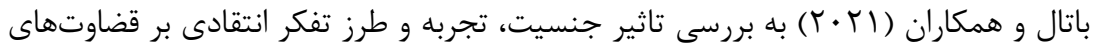

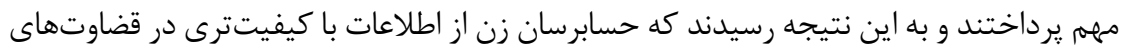
خود استفاده مى كنند.

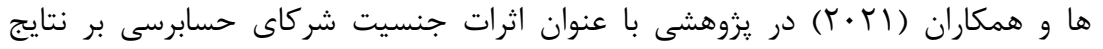

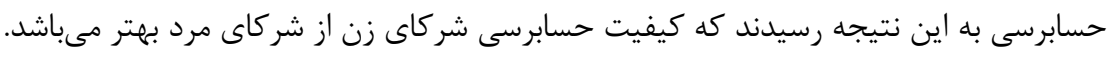

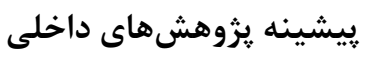

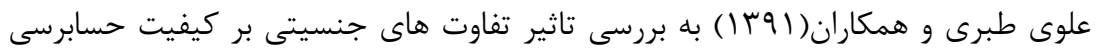

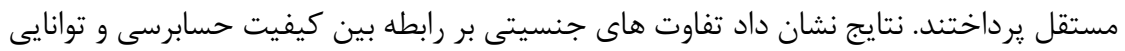

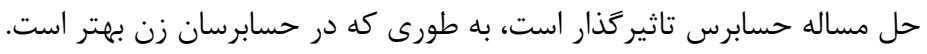

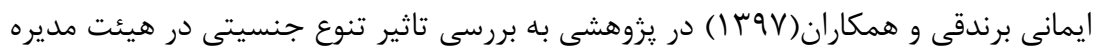

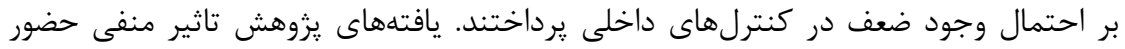

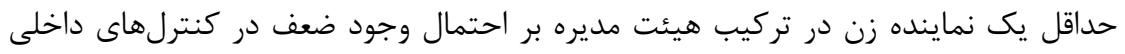

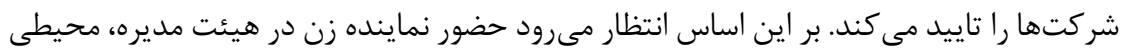
را ايجاد كند كه همخنى هيئت مديره از بين رود و فرآيند كنترل و نظارت دقيقتر كرددد. 
خراشادى و همكاران (191 (I) نشان دادند كه حضور حداقل يك زن در كميته حسابرسى با كاهش ضعف در كنترل هاى داخلى ارتباص مثبت دارد

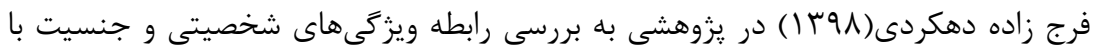

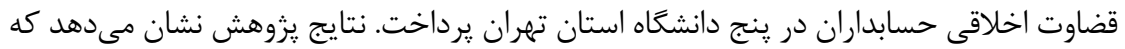
مطابق نظريه نقش جنسيت در فرايند اجتماعى شدن، دانشجويان دختر در مقايسه با دانشجويان يسر كرايش بيشترى به قضاوتهاى اخلاقى دارند.

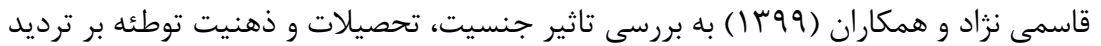

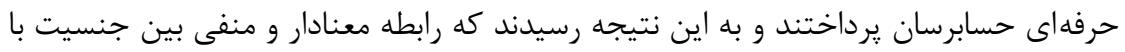

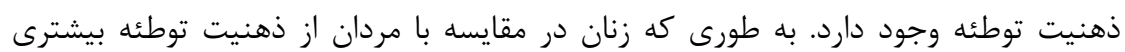

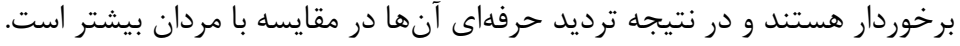

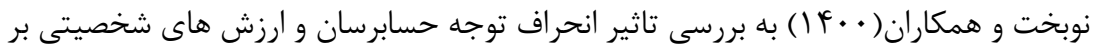

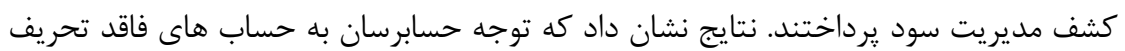
احتمال كشف مديريت سود را كاهش مى دهد و زمانى كه توجه حسابرسان به حساب هاى دارئ دارئ

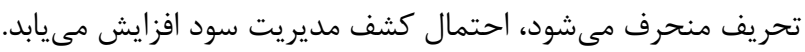

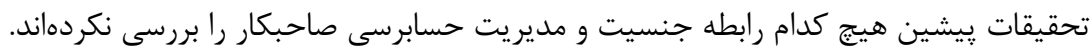
يافتهاى يزوهش حاضر به توسعه ادبيات حوزه رفتارى حسابرسى و نظريههاى مربوط به به آن

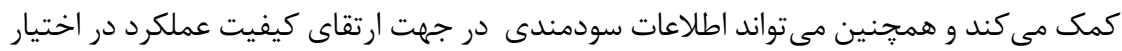
جامعه حسابداران رسمى و موسسات حسابرسى قرى مرار دهد.

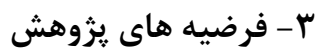

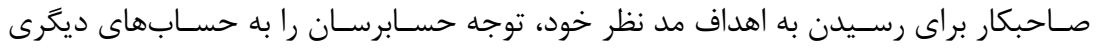

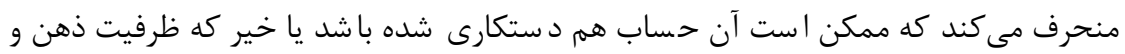

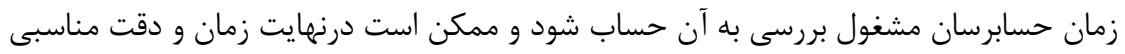

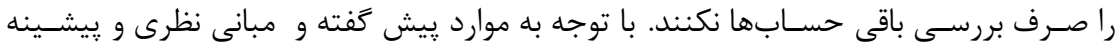

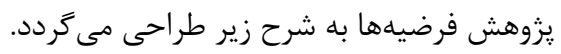

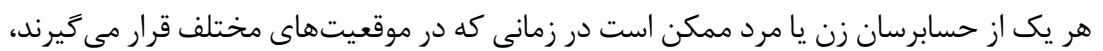

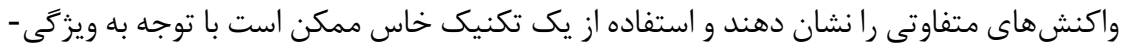

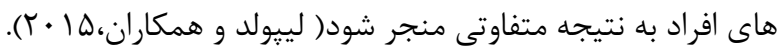

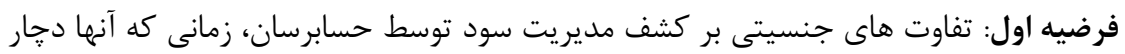
مديريت حسابرسى صاحبكار نمىشوند، تاثير دارد. 
جنان جه فكر حسابرسان به حسابهاى پاك (عارى از تحريف) معطوف شود، ممكن است

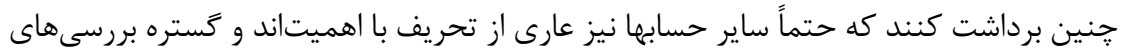

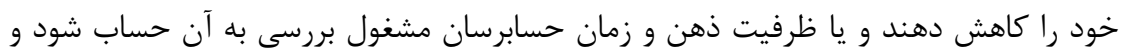
ممكن است درنهايت زمان و دقت مناسبى را صرف بررسى باقى حسابها نابن نكنندا ليبيولد و

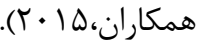
فرضيه دوم: تفاوت هاى جنسيتى بر كشف مديريت سود توسط حسابرسان، زمانى كه فكر آنها به حسابهاى عارى از خطا معطوف مى شود، تاثير دارد.

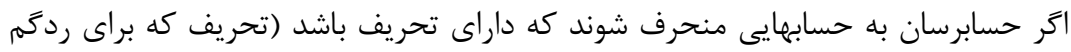

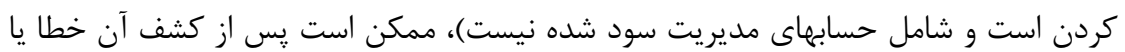

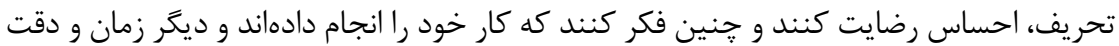

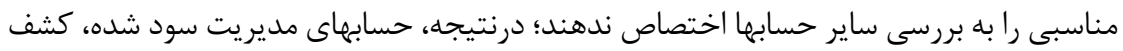

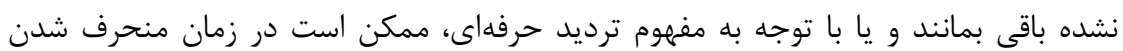

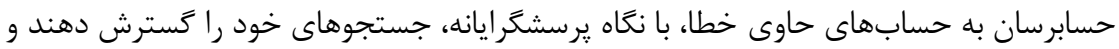

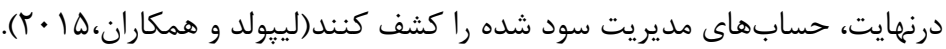

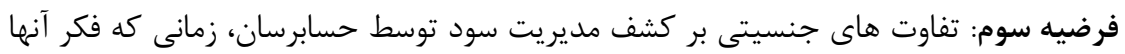
به حسابهاى تحريف شده معطوف مى شود، تاثير دارد.

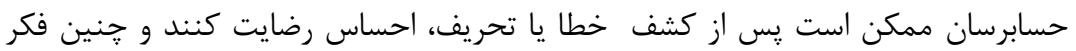

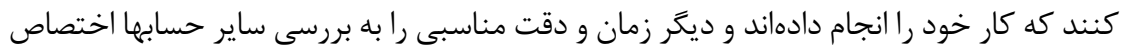
ندهند؛ درنتيجه، حسابهاى مديريت سود شده، كشف نشده باقى بمان

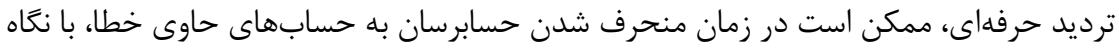

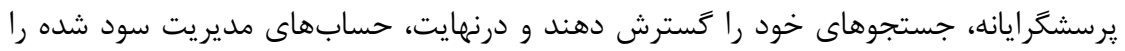

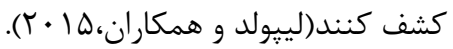
فر ضيه جهارم: تفاوت هاى جنسيتى بر كشف مديريت سود تو سط حسابر سان، زمانى كه فكر

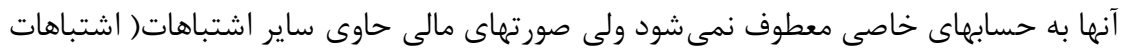
طعمهاى) دريافت كردهاند، تاثير دارد.

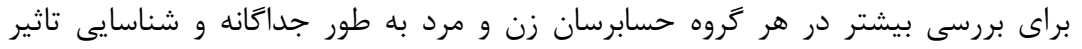

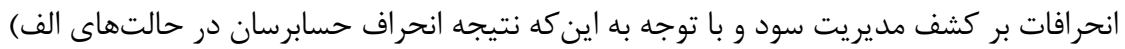
انحر اف حسابرس به سمت حسابهاى عارى از خطا(ياك)، ب) انحراف به سمت ساير اشتباهات و ونائ ج) عدم وجود انحراف در صورتهاى مالى مشخص نمىباشد و رفتار حسابرسان در هر سناريو ممكن است متفاوت باشد، فرضيداى به شكل زير طرح شور شده است: 
فرضيه ينجم: كشف مديريت سود توسط حسابرسان موقعى كه تمركز فكرشان به سمت حساب-

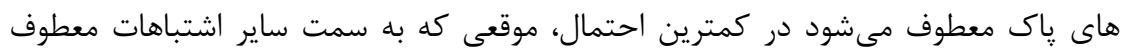

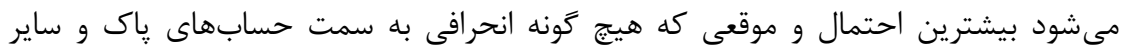
اشتباهات وجود ندارد، مابين اين دو احتمال است.

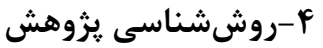

يزووهش حاضر از نظر هدف بنيادى و از ديدكاه ماهيت و نحوه جمع آورى دادهها از نوع نيمه

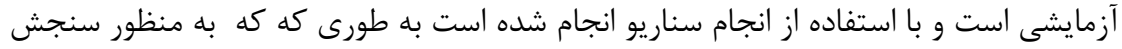

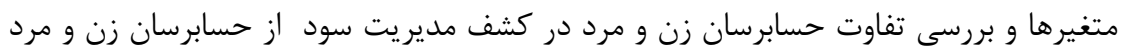

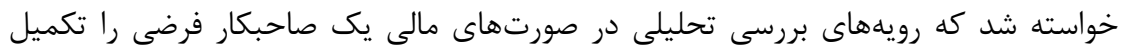

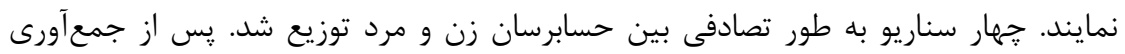

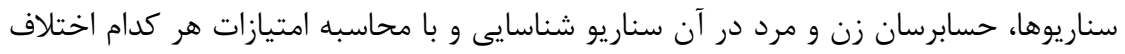

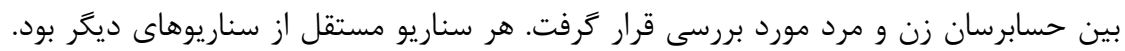

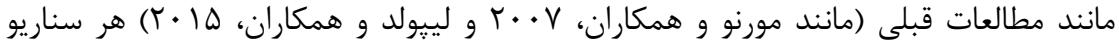

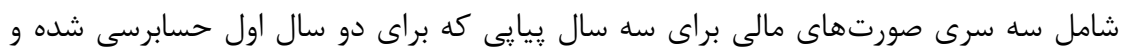

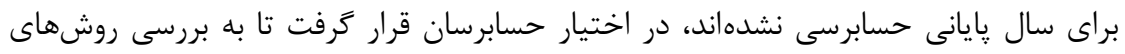

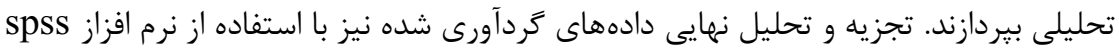

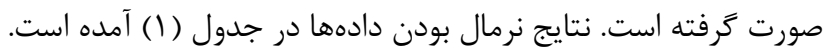
جدول (1): نتايج آزمون كلموكروف - اسميرنوف دادول

\begin{tabular}{|c|c|c|}
\hline Statistic & P-value & صور تهاى مالى \\
\hline$\pi \cdot \Lambda$ & TH & حاوى خطاى خنثى - كروه زنان \\
\hline$|r|$. & $|r|$ & بدون خطاى خنثى - كروه زنان \\
\hline 1119 & / & حاوى جمله منحرف كننده- كروه زنان \\
\hline RT. & 111 & بدون جمله منحرف كننده- گروه زنان \\
\hline $14 \cdot 9$ & / & حاوى خطاى خنثى - كروه مردان \\
\hline $1 \pi \cdot 9$ & 119 & بدون خطاى خنثى - كروه مردان \\
\hline I\AV & $1 \mathrm{M}$ & حاوى جمله منحرف كننده- كروه مردان \\
\hline /TIA & /Ir & بدون جمله منحرف كننده - كروه مردان \\
\hline
\end{tabular}

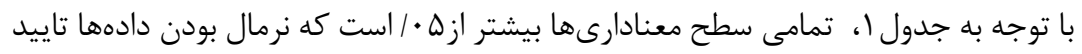

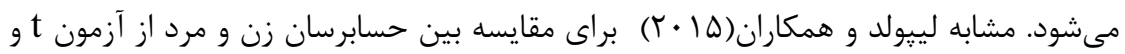


براى مقايسه و بررسى احتمال كشف مديريت سود در حالتهاى انحراف به سمت حسابهاى

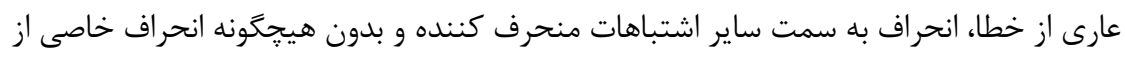
آناليز واريانس استفاده مىشود.

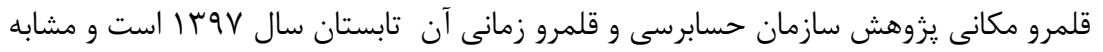

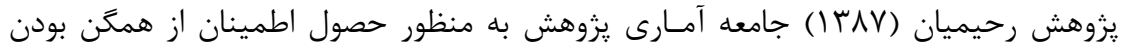

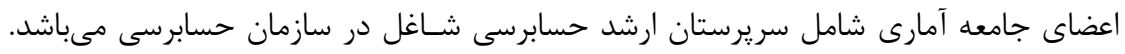
در اين يزوهش نمونه گيرى غير تصادفى از نوع در دسترس انجام مى شود و و لذا، كليه اعضاى

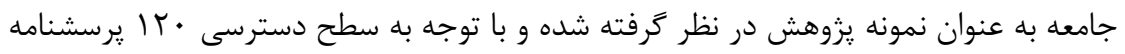

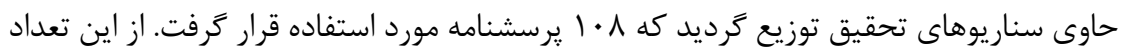

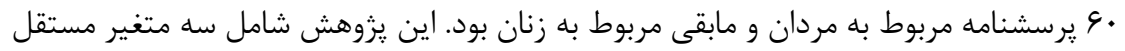

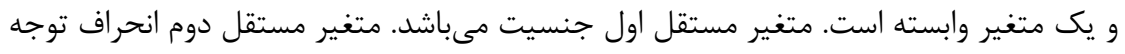

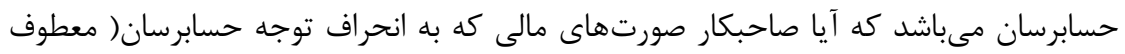

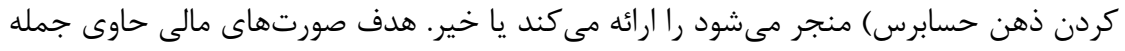

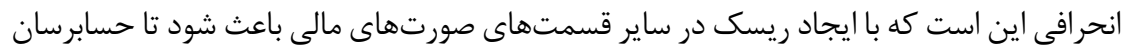

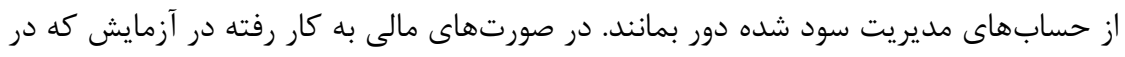

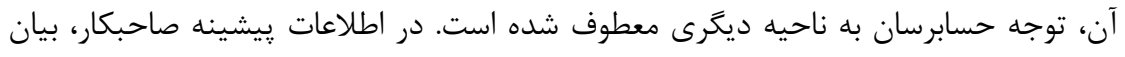

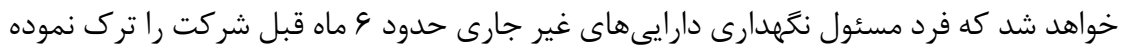

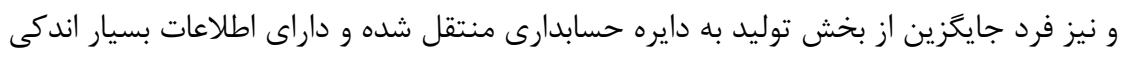

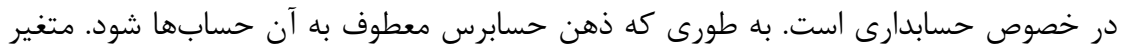

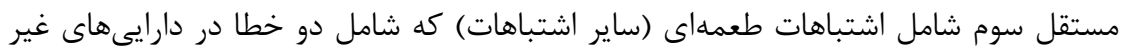

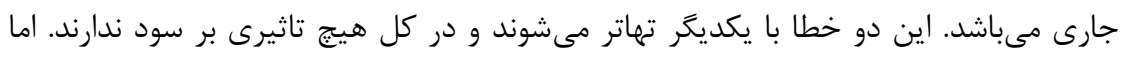

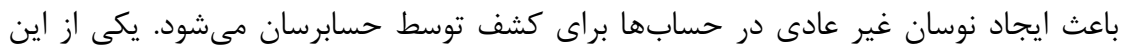

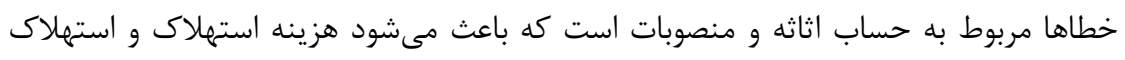

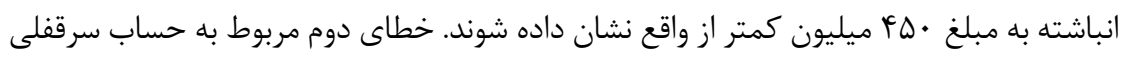

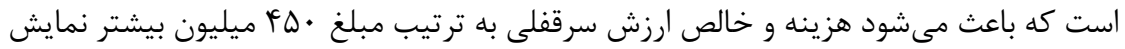

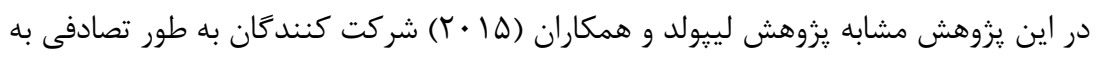

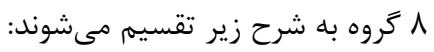

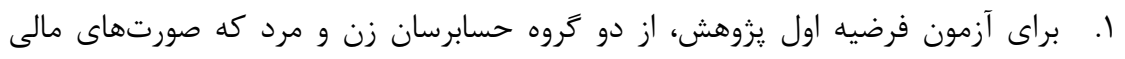

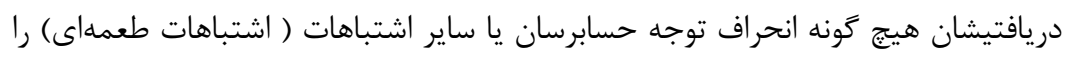


ندارد استفاده شده است (عدم وجود مديريت حسابرسى). صورتهاى مالى يكسان بين اين

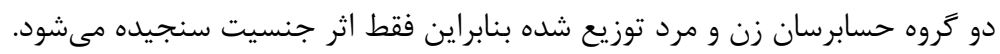

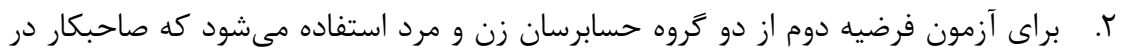

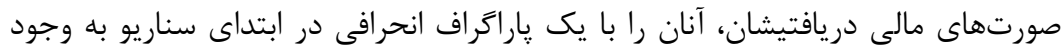

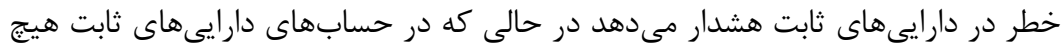

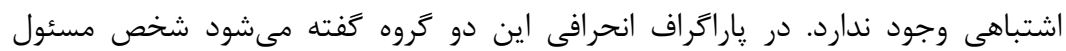
دارايىهاى غيرجارى شش ماه بيش شركت را ترك نموده است و شخص جايكزين و وى

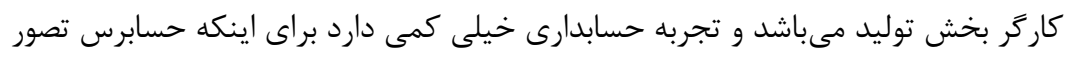

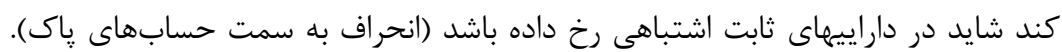

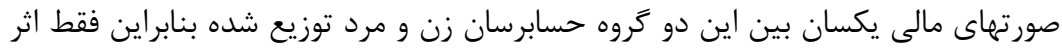
جنسيت سنجيده مىشود. r. براى آزمون فرضيه سوم از دو كروه حسابرسان زن و و مرد استفاده مىشود كه صاحبكار در

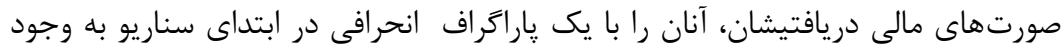

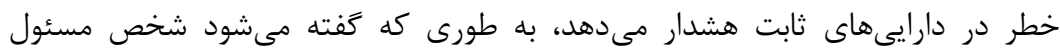

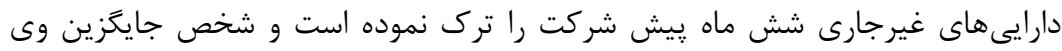

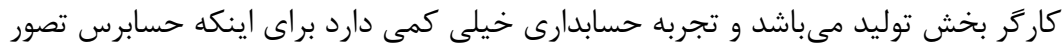

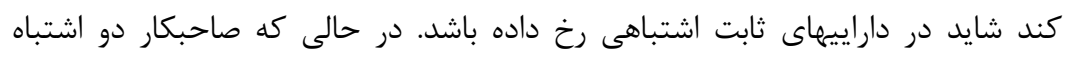

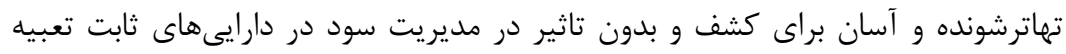

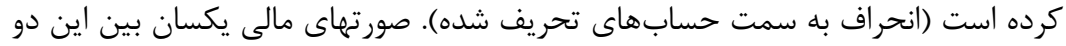

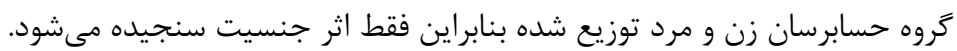

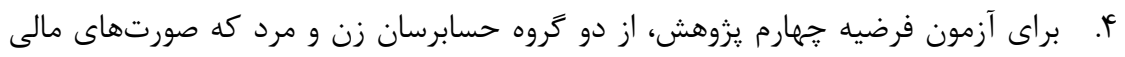

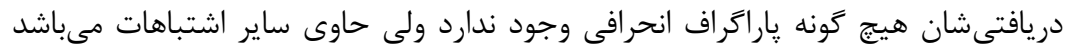

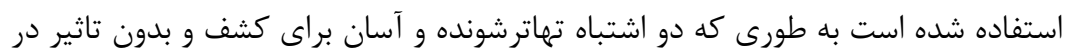

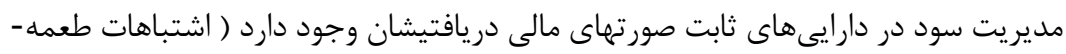

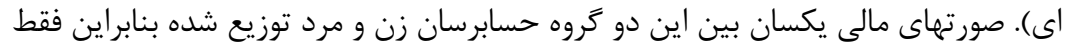

$$
\text { اثر جنسيت سنجيده مىشود. }
$$

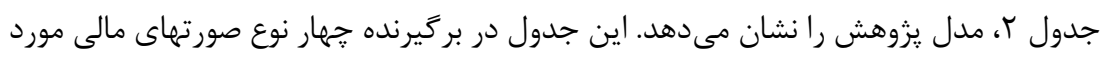

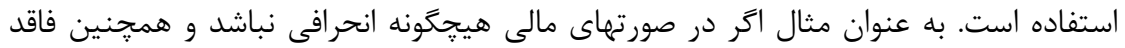

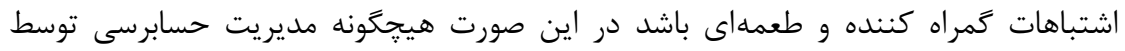

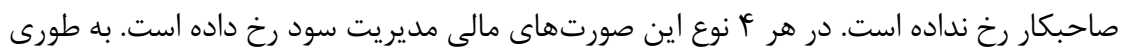


كه هزينه حقوق و مزاياى كاركنان توسط صاحبكار شركت به مبلغ •هأ ميليون كمتر شناسايى

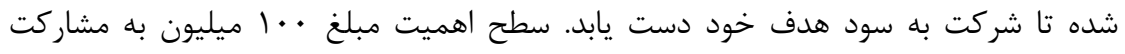

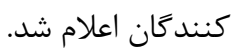

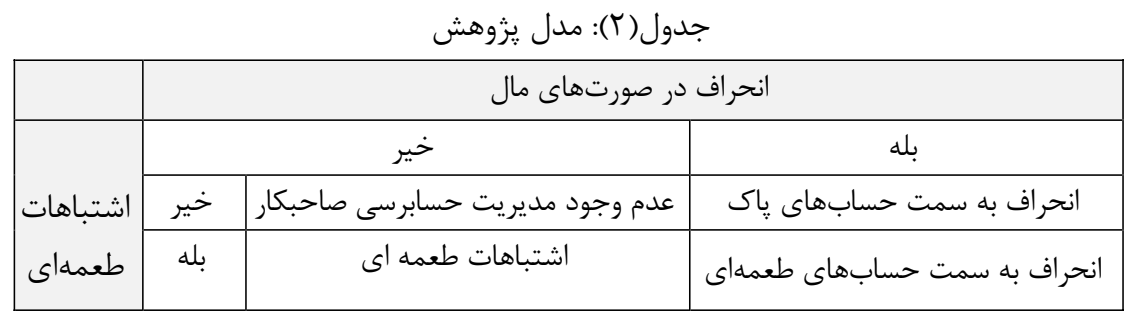

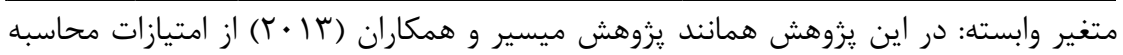

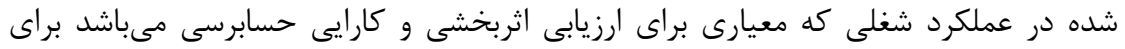

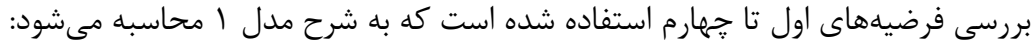

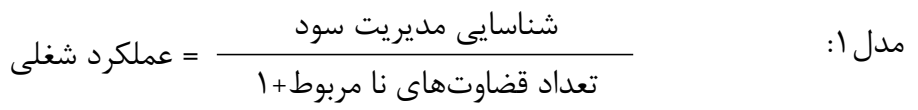

اخر حسابرس يك يا جند حساب از حسابهايى كه به منظور مديريت سود، ماندهشان تغيير

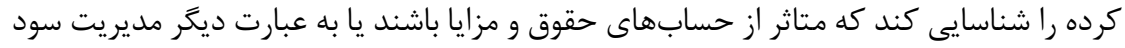

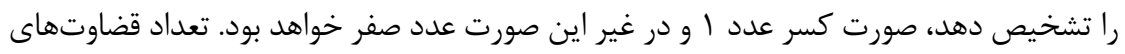

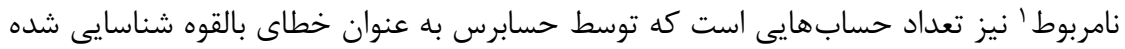

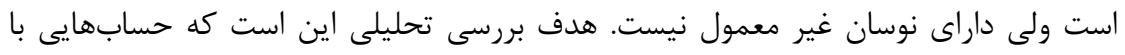

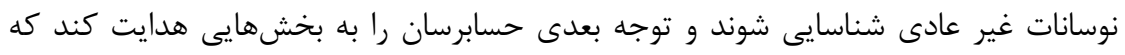

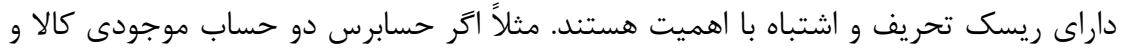
حسابهاى دريافتى را به عنوان حسابهاى بالقوه اشتباه در نظر بخيرد، تعداد قضاوتهاى نامربوط همين دو حساب مى باشد.

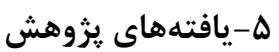

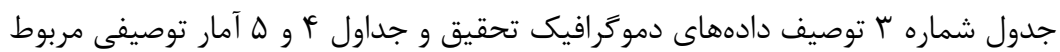

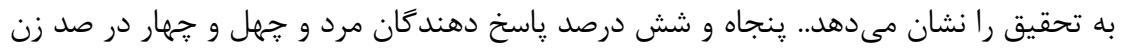

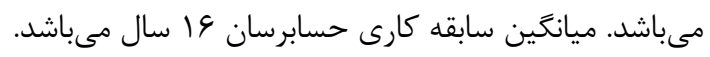

${ }^{1}$ Irelevant Judgment 
جدول (זّ): مشخصات دموگرافيك براى نمونه مورد بررسى

\begin{tabular}{|c|c|c|c|}
\hline درصد & فراوانى & كروه & متغير \\
\hline$\cdot 109$ & 4. & مرد & \multirow{2}{*}{ جنسيت } \\
\hline$\cdot / F F$ & i^ & 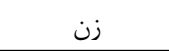 & \\
\hline (r/ן & ra & كارشناسى & \multirow{3}{*}{ سطح تحصيلات } \\
\hline$\cdot 19$ & $9 \Delta$ & كارشناسى ارشد & \\
\hline$\cdot 1 \cdot V$ & $\wedge$ & دكترى & \\
\hline.$/ 1 T$ & Ir & كمتر از هـ & \multirow{3}{*}{ سن } \\
\hline$\cdot / 4$ & ff & از & \\
\hline$\cdot / 4 \lambda$ & DI & بيش از & \\
\hline $1 \cdots$ & $1 \cdot 1$ & \multicolumn{2}{|c|}{ جمع } \\
\hline
\end{tabular}

جدول(f): ميانگين و (انحراف معيار) امتيازات به متغير عملكرد شغلى و تعداد افراد نمونه زنان

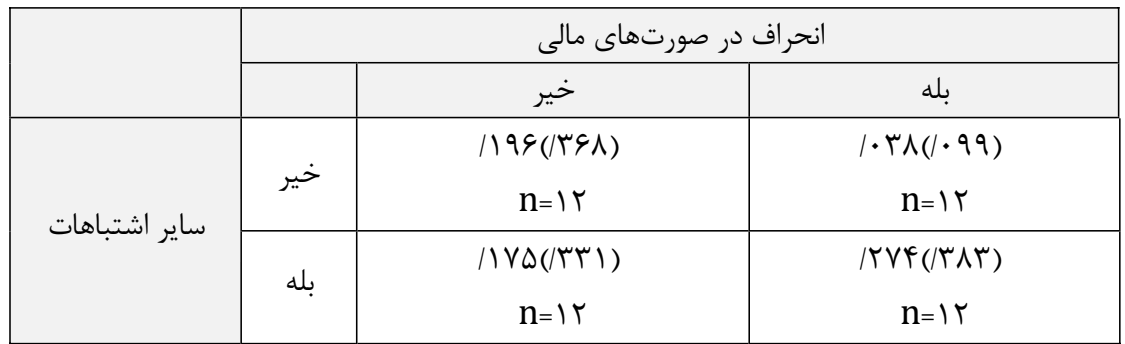

در جدول أ تعداد نفرات شركت كننده در هر سناريو، ميانگين امتياز نفرات شركت كننده

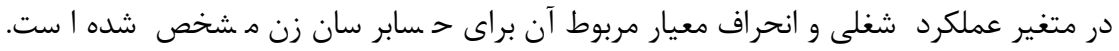

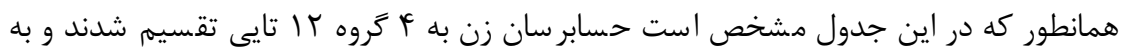

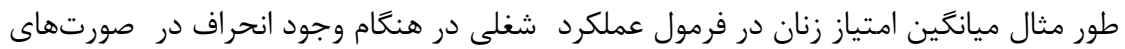

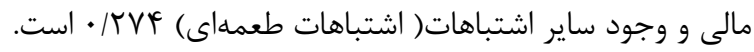
جدول(ه): ميانغين و (انحراف معيار) امتيازات به متغير عملكرد شغلى و تعداد افراد نمانيات نمونه مردان

\begin{tabular}{|c|c|c|c|}
\hline & \multicolumn{3}{|c|}{ انحراف در صورتهاى مالى } \\
\hline & & خير & بله \\
\hline \multirow{2}{*}{ ساير اشتباهات } & خير & $\begin{array}{c}.1 \cdot 1(/ \mu 7 \varepsilon) \\
n=10\end{array}$ & $\begin{array}{c}\because 107(/ \cdot V V) \\
n=10\end{array}$ \\
\hline & بله & $\begin{array}{c}\because 1 \cdot r(/ \Gamma r \cdot) \\
n=10\end{array}$ & $\begin{array}{c}\because 19 \wedge(/ / 11) \\
n=10\end{array}$ \\
\hline
\end{tabular}


در جدول ه تعداد نفرات شركت كننده در هر سناريو، ميانگين امتياز نفرات شركت كننده در

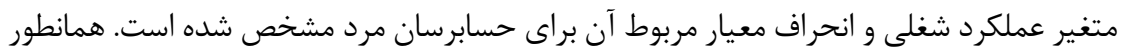

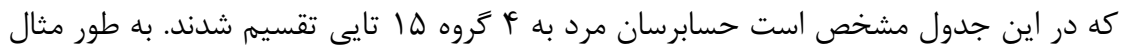

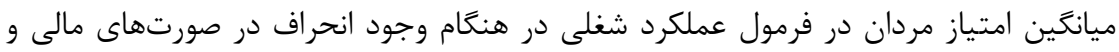

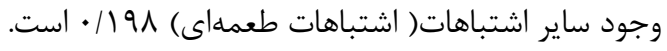

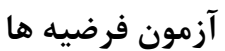

براى بررسى فرضيههاى اول تا جهارم از آزمون آمارى تى استفاده شده است. براى مشاهده اينكه

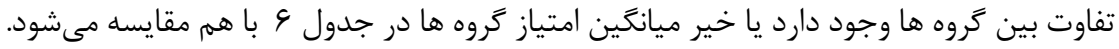

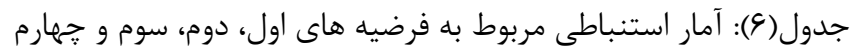

\begin{tabular}{|c|c|c|c|}
\hline |نتيجه در سطح | اطمينان هـ/ & معنادارى سطح & $\begin{array}{c}\text { آمار0 } \\
t\end{array}$ & فرضيه \\
\hline تاييد & . / r. & $r / \Lambda \Delta$ & 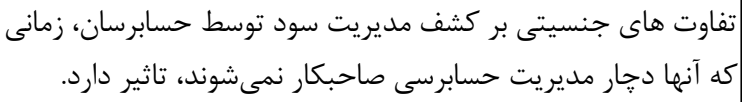 \\
\hline تاييد & $.1 \cdot T V$ & $\mathrm{~m} / \mathrm{s}$ & 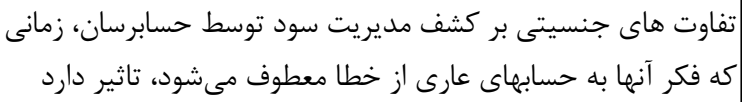 \\
\hline تاييد & $\cdot 1 \cdot 49$ & $T / f \mid$ & كه فكر آنها به حساى جنسيتى بر كشف مديريت سود توسط حسابرسان، زمانى تحريف شده معطوف مىشود، تاثير دارد. \\
\hline تاييد & $\cdot / \cdot r \Delta$ & $1 / 91$ & 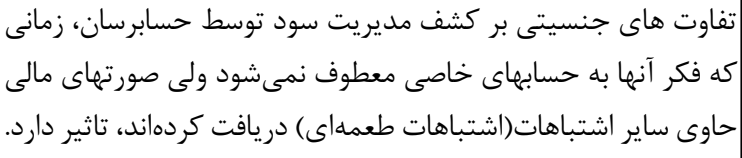 \\
\hline
\end{tabular}

با توجه به جدول و، تفاوت هاى جنسيتى اثر معنادارى در مديريت حسابرسى و كشف مديريت

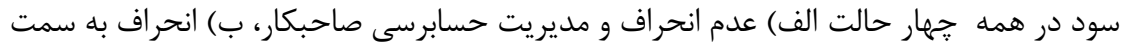

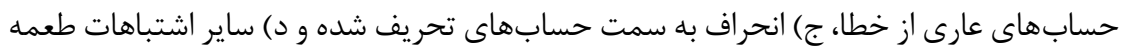

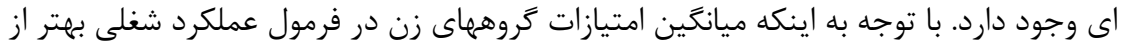

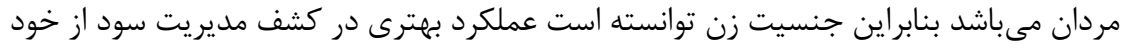

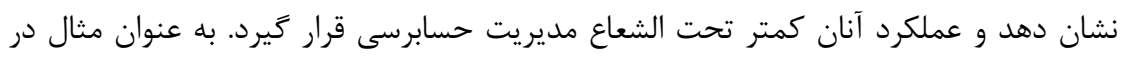

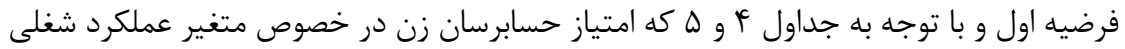

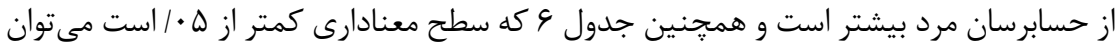

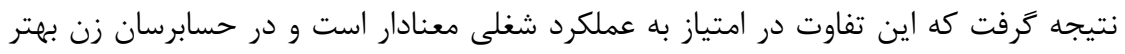




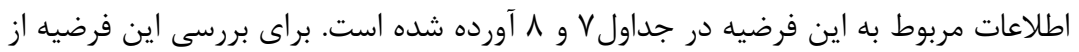

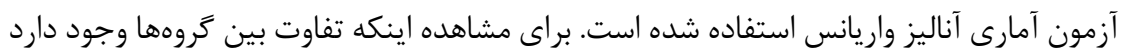

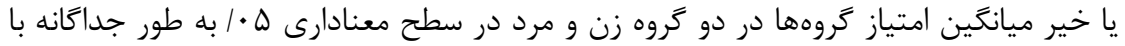
هم مقايسه مىشود.

\begin{tabular}{|c|c|c|c|c|c|}
\hline \multicolumn{6}{|c|}{ جدول(V): آزمون آمارى كروه زنان } \\
\hline سطح معنادارى & $\begin{array}{c}\text { آماره } \\
\text { F }\end{array}$ & مربعات & دآزادى & مربعات & شرح \\
\hline $.1 \cdot \varphi^{2}$ & $1 / r \cdot V$ &.$/ .14$ & 1 &.$/ .14$ & نحراف به سمت حسابهاى عارى از خطا \\
\hline $.1 \cdot 1$ & $r / 9 V T$ & 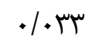 & 1 & س & شتباه طعمهاى \\
\hline \multirow[t]{3}{*}{.$/ .1$} & \multirow[t]{3}{*}{$9 / 9 \vee 9$} &.$/ \cdot 1 \mu$ & 1 & $\cdot / \cdot \Lambda \mu$ & جمله منحرف كننده×خطاى طعمهاى \\
\hline & & .1 .19 & per & $\cdot / N \mu$ & خطا \\
\hline & & & 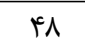 & $1 / \cdot V$ & كل \\
\hline
\end{tabular}

جدول(^): آزمون آمارى كروه مردان

\begin{tabular}{|c|c|c|c|c|c|}
\hline معنادارى سطح & $\mathrm{F}$ & آزادى درجه & دآزادى & جرمعات & 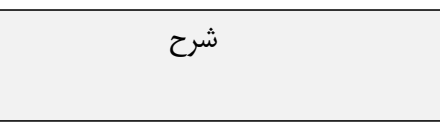 \\
\hline $.1 \cdot 40$ & $\cdot 1 / 4 \cdot 9$ &.$/ .14$ & 1 &.$/ .14$ & انحراف به سمت حسابهاى عارى از خطا \\
\hline.$/ \cdot r$ & $. r / Q \wedge \uparrow$ &.$/ \cdot M F$ & 1 &.$/ . \mu \mathrm{C}$ & اشتباه طعمهاى \\
\hline \multirow[t]{3}{*}{.$/ . \cdot r$} & \multirow[t]{3}{*}{ १/१८१ } &.$/ \cdot 11$ & 1 & $\cdot / \cdot 11$ & جمله منحرف كننده*:خطاى طعملى \\
\hline & & .1 .14 & $\Delta \varphi$ & $\cdot / N M T$ & خطا \\
\hline & & & q. & $1 / \cdot 9$ & كل \\
\hline
\end{tabular}

نتايج در جداول \و ^ نشان مى دهد كه معنادارى براى هر دو حالت مقايسه( براى مردان و زنان

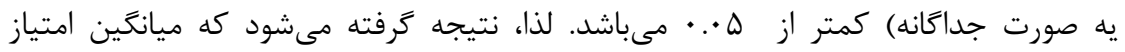

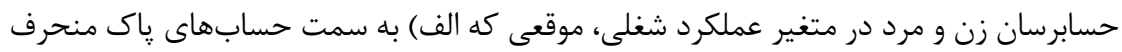

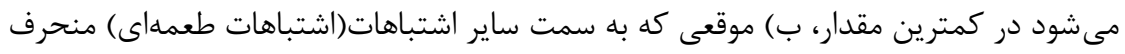

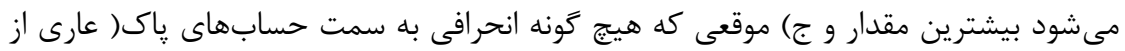

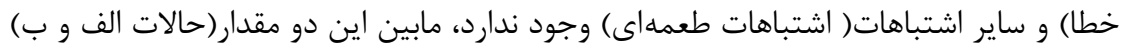

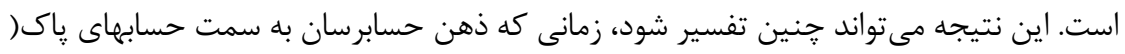

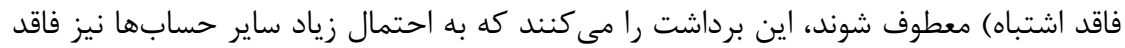
تحريف هستند و دامنه رسيدگى هاى خود را گسترش نمىدهند و در نهايت مديريت سود با باليا 
احتمال كمترى كشف مىشود. در صورتى كه توجه حسابرسان به حسابهاى حاوى اشتباه گمراه

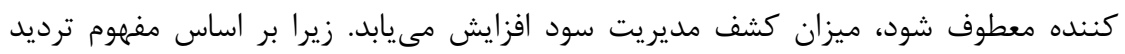

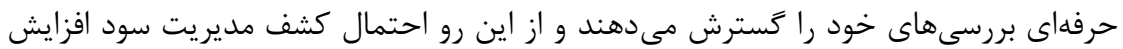

به طور كلى، كشف مديريت سود موقعى كه حسابرسان به سمت حسابهاى ياك إى (بدون اشتباه) سوق داده مىشدند در كمترين احتمال، موقعى كه به سمت ساير اشتباهات (بدون تأثير مديريت سود) سوق داده مىشدند در بيشترين احتمال و موقعى كه هيج كونه انحر افى به همراه

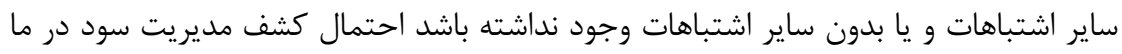
بين دو حالت كفته شده در بالا قرار دارد.

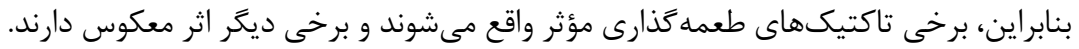

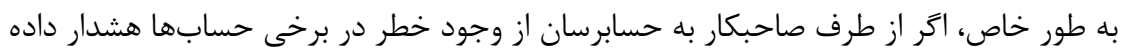

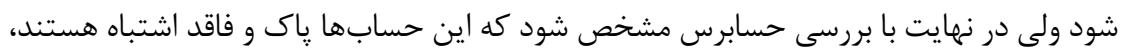
اثر بخشى حسابرسان در كشف مديريت سود كاهش بيدا مى كند و استفاده از اين تاكتيك براى

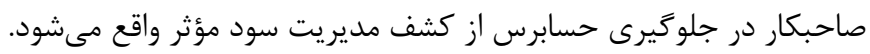

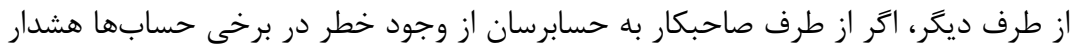
داده شود و در نهايت با بررسى حسابرس مشخص شود كه اين حسابها واقعا داراى اشتباه

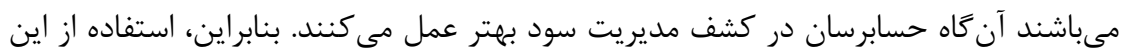

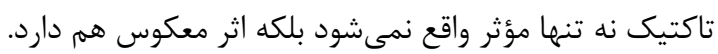

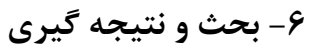

يزوهش حاضر تاثير جنسيت بر مديريت حسابرسى و كشف مديريت سود دون توسط حسابرسان

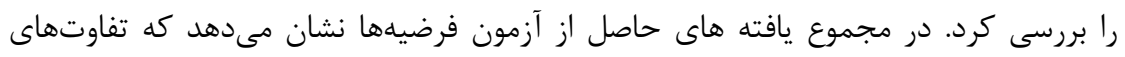

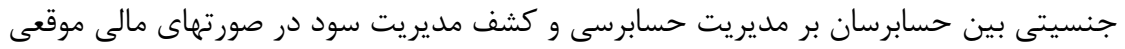

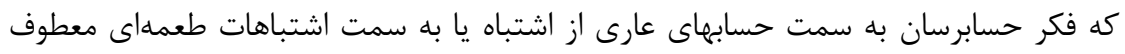

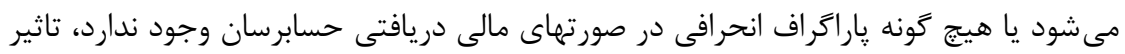
دارد و عملكرد حسابرسان زن در اين زئ زمينه

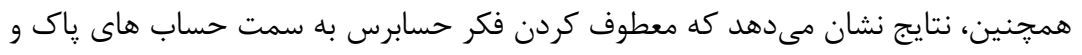
انحراف حسابرس به سمت ساير اشتباهات( اشتباهات طعمهاى) اثرات متفاوتى بر روى تشخيص

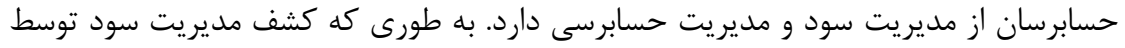

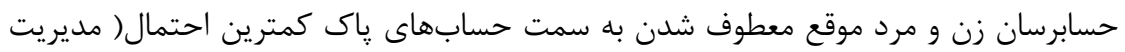


حسابرسى توسط صاحبكار موثر واقع شده) و موقع معطوف شدن به سمت ساير حساب ها

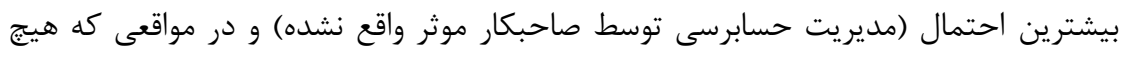

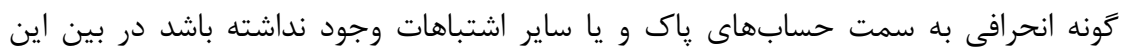
احتمالات قرار دارد.

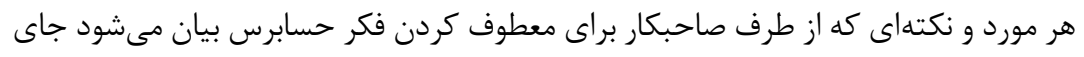

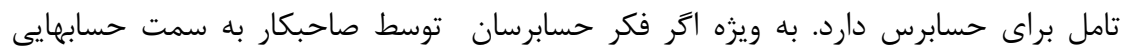

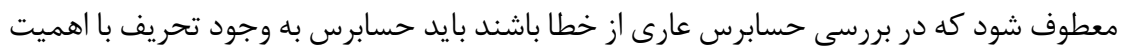

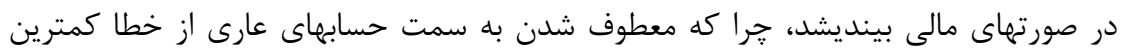

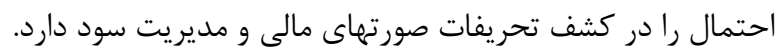

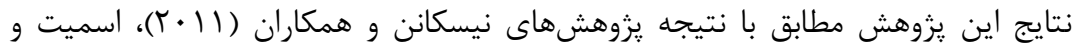

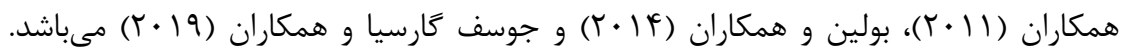

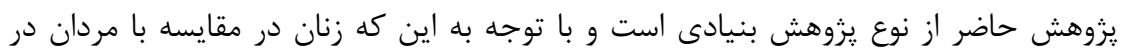

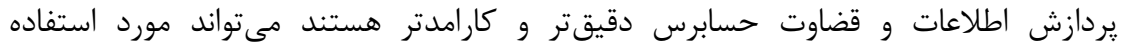

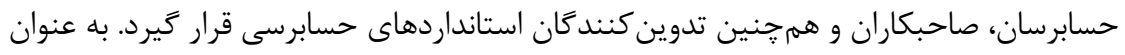

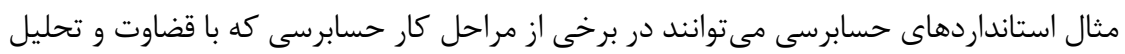

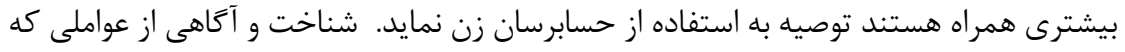

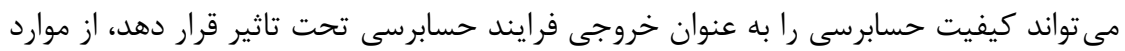

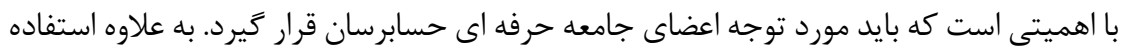

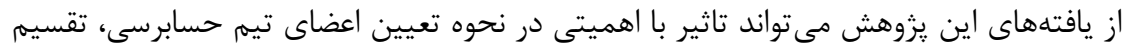

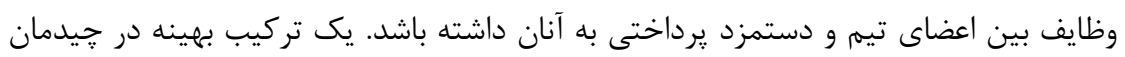

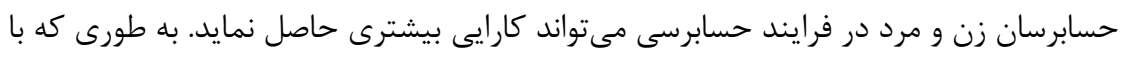

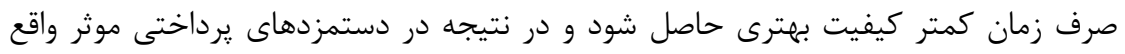

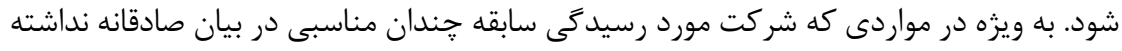

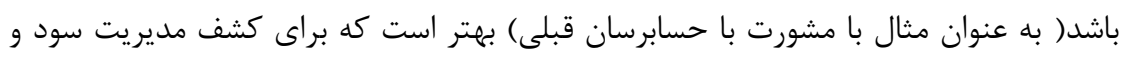

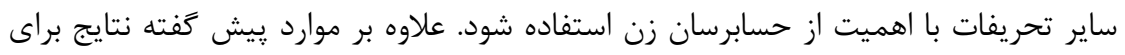

$$
\text { سازمانها و اشخاص زير نيز قابل استفاده است. }
$$

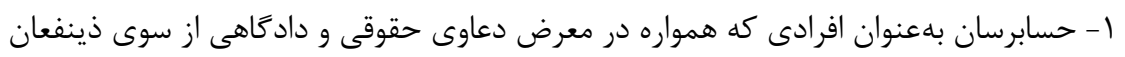

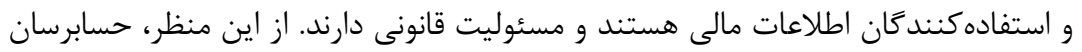

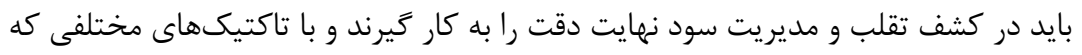


از طرف صاحبكار جهت فريب خود مواجه هستند، آشنا شوند. موسسات حسابرسى با توجه

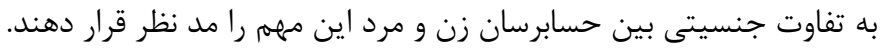

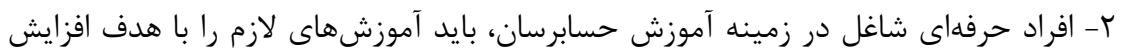

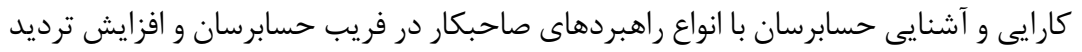

حرفهاى حسابرسان صورت دهند.

اين تحقيق نيز همانند ساير تحقيقات با محدوديت هايى مواجه بوده است. به عنوان مثال ممكن

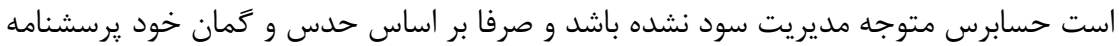

را ير نموده باشد.

V- تقدير و تشكر و ملاحظات اخلاقى

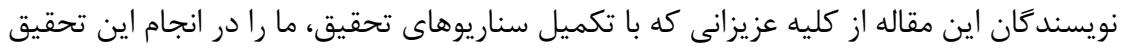

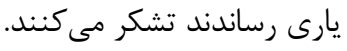

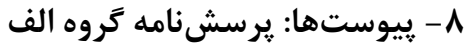

\section{عدم مديريت حسابرسى}

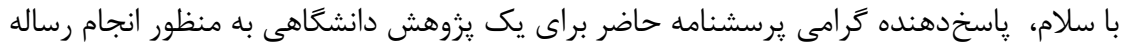

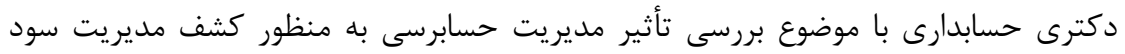

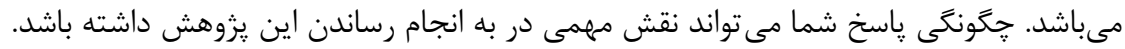

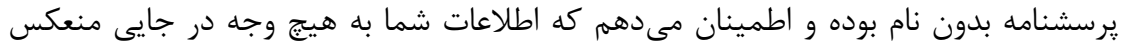

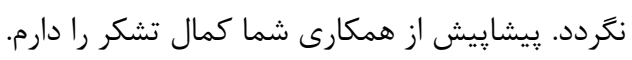

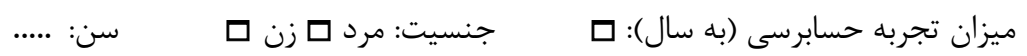

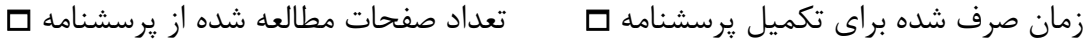

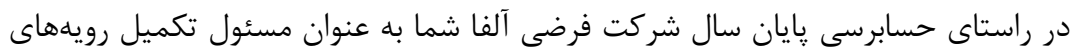

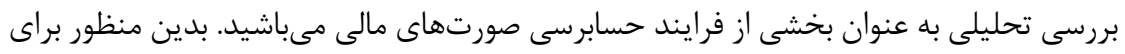

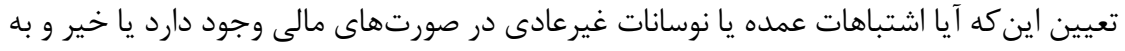

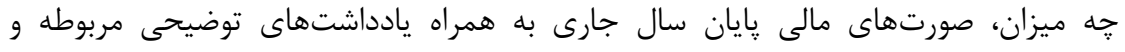

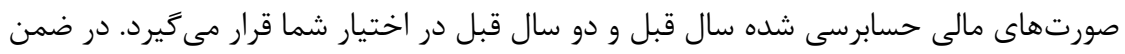

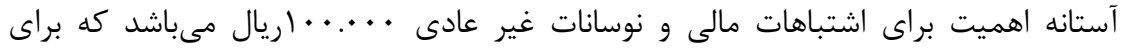

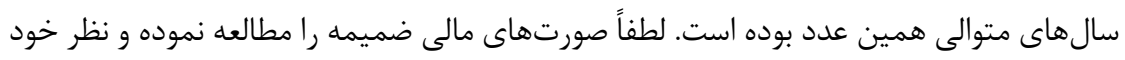

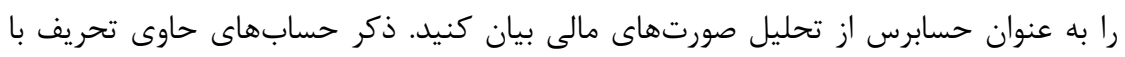


اهميت و حسابهايى كه به طور بالقوه امكان اشتباه در آنها وجود دارد (در صورت وجود) در صفحه آخر الزامى مىباشد

ترازنامه

\begin{tabular}{|c|c|c|c|c|c|c|}
\hline \multicolumn{2}{|c|}{ حسابرسى شده دو سال } & \multicolumn{2}{|c|}{ حسابرسى شده سال قبل } & \multicolumn{2}{|c|}{ سال جارى حسابرسى نشده } & \multirow[b]{2}{*}{ دار ايیىها } \\
\hline كل دارايىها & (رقدار) & كل دارايىها & مقدار & كل دارايیى ها & مقدار & \\
\hline$\%$ & 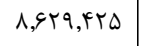 & $\% .9$ & $\Lambda, \zeta \vee V, r \Delta \cdot$ & $\% 9 . \%$ & $\Lambda, q r \cdot, \cdot \vee \cdot \vee$ & نقد \\
\hline$\%$ T.r & $r, \mid q 4, I V$. & $\%$ H.r & $r, 19 \cdot, r F r$ & $\% . r . t$ & ५, Y४q,११V & |وراق بهادار قابل معامله \\
\hline$\%$ \%G.F & rF, $\Delta \Delta \Delta, r \& Y$ & $\%$ TY.Y & $r F, g \mid r, V M I$ & $\%$ \% & $r r, q 9 \cdot, q r q$ & خالص حسابهاى دريافتنى \\
\hline 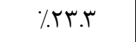 & YI,VFI, $9 \wedge \mathrm{V}$ & מ.T.T. & $r \mid, V \in V, r \Delta I$ & D.t.t. D & $r|, \wedge| f, q \vee 9$ & موجودى كالا (FIFO) \\
\hline$\%$ r.f & T,YT,I\&V & $\%$ r. $\Delta$ & 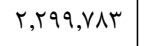 & $\%$ T.Y & 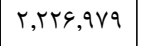 & 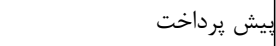 \\
\hline \%.ร.V & ט9,זrT,V।I & $\% .94 .9$ & $\Delta q, \digamma q \vee, r \Delta \vee$ & $\% .94 .1$ & $\Delta ৭, \Delta \vee \Psi, F \wedge \Delta$ & جمع دارايى هاى جارى \\
\hline$\%$ H.d. & $r r, 1 \cdot 9, r F q$ & $\%$ H. & $r T, r \cdot \Delta, F^{\prime}$ & $\%$ HF.V & TT,YFV, ९qq & موال، ماشينآلات و تجهيزات \\
\hline$\% . \Delta . f$ & $-\Delta, \cdots \varphi, \vee \Delta \mu$ & $\% . \Delta .9$ & $-\Delta, r \cdot 9, \wedge \Delta r$ & $\% \Delta \cdot \Lambda$ & $-\Delta, r r \Delta, \cdot v r$ & كسر مىشود: استهلاكى انباشته \\
\hline$\%$ \% & $r v, \cdot 9 १, \Delta ৭ 1$ & $\%$ \% . & 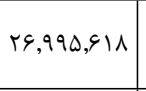 & $\%$ \%^.^ & 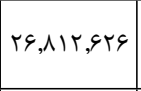 & 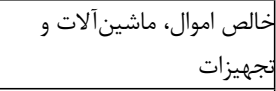 \\
\hline$\%$ & $1, \wedge \Lambda \cdot, 1 \cdot \uparrow$ & $\% 1.9$ & $1, \vee \Delta T, \Delta \wedge \varphi$ & $\% 1 . V$ & $1,949,99$ & خالص دارايىهاى نامشهود \\
\hline$\% . \Delta$ & $\varphi, \wedge f r, \cdot \Delta \varphi$ & $\%$ & $\uparrow, 9 \uparrow \&, \uparrow \& V$ & $\%$ & $\uparrow, १ \Delta \Delta, १ \uparrow \wedge$ & ساير دارايىهاى غيرجارى \\
\hline \multirow[t]{2}{*}{$\% \cdots$} & $q 4, \mid f \&, f \& r$ & $\% 1 \cdots$ & $q r, I V I, \wedge r V$ & $\% 1 \cdots$ & $9 r, q \& \vee, 1 \cdot \wedge$ & مجموع دارايىها \\
\hline & & & & \multicolumn{3}{|c|}{ بدهى ها و حقوق صاحبان سرمايه } \\
\hline$\% 10.1$ & $\mid f, \cdot r \wedge, f \cdot \varepsilon$ & $\% 10$. & $|f, \cdot| 1, q \cdot 1$ & $\% 10.5$ & $|f, \cdot 9 \vee, \xi| \wedge$ & حسابهاى يرداختنى \\
\hline$\% \cdot .9$ & $\Lambda \cdots, r G$. & $\% \cdot .9$ & $\Lambda I V, \Delta F V$ & $\% \cdot \Lambda$ & $\vee \wedge ৭, F \vee f$ & ماليات يرداختنى \\
\hline$\% .9 .4$ & $\wedge, \vee \Delta \perp, \cdot 9 \wedge$ & $\% .9 .4$ & $\wedge, \vee \wedge \Lambda, \vee Y \uparrow$ & $\% .9 .4$ & $\wedge, ९ 99, ı \vee r$ & سناد يرداختنى كوتاهمدت \\
\hline$\%$ \% D & $r, Y \backslash V, \mathcal{F} \cdot \varepsilon$ & $\%$.t.f & $r, l \Delta \xi, q \notin V$ & $\%$ & $r, \cdot 11, r q 1$ & حصه جارى بدهيهاى بلندمدت \\
\hline$\%$ \%.9 & $\Lambda, r \mid f, \cdots q$ & $\%$ & $\wedge, r<q, \vee q$. & $\%$ \%.१ & $\Lambda, 1 F V, I F G$ & ساير بدهى هاى جارى \\
\hline \% r.V.V & $r \Delta,|r|, I \vee \wedge$ & $\%$ rV.V & $r \Delta,|r|, q \cdot q$ & $\%$ HV.f & $r f, \wedge \mid f, V \cdot 1$ & جمع بدهى هاى جارى \\
\hline \% & $11, \Delta \cdot r, f \wedge 9$ & $\%$ It.t & $11, \Delta \mathcal{F} \Delta, r \Delta F$ & $\%$ & $11,9 \cdot 9, \cdot 11$ & لدهىى هاى بلندمدت \\
\hline$\% 4.9$ & $f, \Delta r \cdot, f \Psi \Lambda$ & $\% \uparrow .1$ & $f, \uparrow \wedge \Delta, q \wedge$. & $\% \notin .4$ & F,YNI, KYA & ساير بدهى هاى غيرجارى \\
\hline$\%$ & $f, \uparrow \Delta \cdot, \cdots$ & $\%$ & $f, q \Delta \cdot, \cdots$ & $\%$ & $\uparrow, १ \Delta \cdot, \cdots$ & سهرام عادى \\
\hline$\%$ \%१.१ & $r v, \cdot|f|, r \Delta s$ & $\%$ & $r \vee, \cdot \Delta \Lambda, \Delta \wedge \mathcal{F}$ & $\% \varphi \cdot .1$ & $r V, r \mid T, I 9 \Lambda$ & سود انباشته \\
\hline$\% \notin \Delta .1$ & $f ।, 991, r \Delta \varphi$ & $\% \mp \Delta .1$ & $F r, \cdots \wedge, \Delta \wedge \mathcal{F}$ & $\% \& \Delta . \Delta$ & FTYGTIGA & جمع حقوق صاحبان سهام \\
\hline$\% \cdots \cdot$ & $q \Psi, \mid \uparrow q, \uparrow \& Y$ & $\% 1 \cdots$ & $9 \Psi, \mid \vee \backslash, \wedge T V$ & $\% 1 \cdots$ & $9 r, 9 \& V, 1 \cdot N$ & صمجموع بدهى هاحبان و حقوق \\
\hline
\end{tabular}


دوفصلنامه حسابدارى ارزشى و رفتارى، سال ششم، شماره يازدهم، بهار و تابستان +. عا

\begin{tabular}{|c|c|c|c|c|c|c|}
\hline \multicolumn{7}{|c|}{ صورت سود و زيان } \\
\hline \multicolumn{2}{|c|}{ |حسابر سى شده دو سال قبل } & \multicolumn{2}{|c|}{ حسابرسى شده سال قبل } & \multicolumn{2}{|c|}{ سال جارى حسابرسى نشده } & \\
\hline مقدار & كل دار ايىها & $\begin{array}{l}\text { مقدار } \\
\text { (ريال) }\end{array}$ & مقدار & كل دارايىها & مقدار & \\
\hline$\% \cdot r \cdot 1$ & $|\vee \wedge, \Delta \wedge|, \Delta \cdot \wedge$ & $\% \cdot r .1$ & 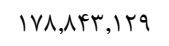 & $\% \cdot r .1$ & $\mid V \Lambda, r q 9, q \cdot r$ & فروش \\
\hline$\% . r .1$ & - & $\% . r .1$ & - & $\%$ \%.1 & $-r, \Delta ৭ ६, \wedge ६$. & فروش و مى تخفيفات برگشت از \\
\hline$\% \cdots$ & $I V \Delta, \cdot \Delta V, g \mid r$ & $\% \cdots$ & IVQ,r·৭,rTG & $\% \cdots$ & $I V F, V \cdots, \cdot F r$ & فروش خالص \\
\hline$\% \vee 1.9$ & $-I r \Delta, r \varepsilon \cdot, r \uparrow q$ & $\% \vee 1 . \Delta$ & $-I T \Delta, r \Delta T, \Lambda \Delta T$ & $\%$ \% I.V & $-\mid r \Delta, r \Delta V, \cdot \varphi \cdot$ & كسر مىشود: بهاى تمام \\
\hline$\%$ \%A. F & ६q,Vq४,rqץ & $\%$ \% & $\uparrow q, \wedge \Delta \Delta, F \vee F^{F}$ & $\%$ \% & $q q, f \notin \mu, \cdot r$ & سود ناخالص \\
\hline$\% \cdot r \cdot \Lambda$ & $-r \varphi, r \Delta V, I \Delta r$ & $\% \cdot r \cdot \Lambda$ & $-r \xi, r \vee q, 11 r$ & $\% \cdot r \cdot \Delta$ & $-r \Delta, \Lambda r r, 19 q$ & هزينههاى ادارى و فروش مس \\
\hline$\% . V . V$ & $\|r, f 4 \cdot, r\| \mid$ & $\% . V . V$ & IT,FVG, एGY & $\%$ \%.A & $1 r, q \cdot 9, \wedge r F$ & سود عملياتى \\
\hline$\% \cdot \varphi^{f}$ & $-8 \curlyvee 9, \Delta q$. & $\% \cdot r$ & $-91 \cdot, 9 \cdot 9$ & $\% \cdot r$ & $-9 \cdot 4, r 99$ & كسر مى درود: خالص ساير \\
\hline$\% . \mathrm{Yr}$ & $|r, \wedge| \cdot, g r \mid$ & $\%$ V.r & $\mid r, \wedge \& \Delta, V \Delta \&$ & $\%$ Y.F & $\mid r, \cdot \Delta, \Delta r \Delta$ & سود قبل از كسر بهره \\
\hline$\% \cdot \Delta$ & $-9 \Delta T, r \& V$ & $\% .9$ & -qVG,fसr & $\% \cdot \Delta$ & $-9 \Delta r, \cdot \vee 1$ & كسر مىشود: هزينه بهره \\
\hline$\% .9 .1$ & $11, \wedge \Delta \Lambda, \Upsilon \Delta \Delta$ & $\% .9 .1$ & $11, \wedge \wedge 9, r \| r$ & $\% .9 .9$ & $I T, \cdot \Delta T, F \& Y$ & سود قبل از كسر \\
\hline$\% .1$ & $-r, \xi \mu \wedge, \uparrow \& \Delta$ & $\% . r .1$ & $-r, g \notin t, V \vee q$ & $\% . r .1$ & $-r, \Delta q \vee, F \wedge r$ & كسر مىشود: ماليات \\
\hline$\% \varphi v$ & $\wedge, r \backslash 9, \vee 9$. & $\% \notin . V$ & $\Lambda, Y Y \&, \Delta T \Delta$ & $\% .4$ & $\Lambda, F \Delta F, q \Lambda 1$ & سود خالص \\
\hline
\end{tabular}

صورت جريان وجوه نقد

\begin{tabular}{|c|c|c|c|}
\hline حسابرسى شده & شده سال قبل & حسابرسى نشده & \\
\hline 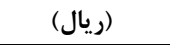 & 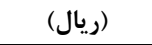 & 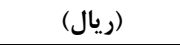 & 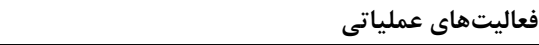 \\
\hline$\wedge, \Upsilon 19, \vee 9 \cdot$ & $\Lambda, r \uparrow \varphi, \Delta r \Delta$ & $\Lambda, F \Delta f, q \Lambda 1$ & 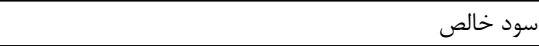 \\
\hline$r, \| Q,, \xi 4 \Delta$ & $r, \mid f q, \cdots r$ & $r, \mid \wedge \Lambda, \Delta T^{\prime}$ & تعديل استهلاك \\
\hline$|r \wedge, \Lambda| V$ & $-\Delta V, \varphi \& q$ & $-4 \wedge, 190$ & تغييرات در حسابهاى دريافتنى \\
\hline$V, r G 4$ & $-\Delta, \Delta \& \varphi$ & $-9 \vee, V T \Delta$ & تغييرات در موجودى كالا \\
\hline FT, rGV & $-99,919$ & $V r, \Lambda \cdot r$ & تغييرات در يِيش يرداخت هزينهها \\
\hline $9 \Delta, r F$. & $F F, r \cdot G$ & $৭ \vee, \wedge \Delta V$ & تغييرات در دارايىهاى نامشهود / ساير دارايىهاى غيرجارى \\
\hline $19, \wedge T \Delta$ & $r r, \Delta G q$ & $-1 \Delta T, \cdot \cdot 1$ & جارى تغيرات در حسابهاى يرداختنى / ماليات و ساير بدهىهاى \\
\hline$\Delta F, \cdot F q$ & $-\psi f, \varphi \Delta \Lambda$ & $-T \cdot Y, V \Delta T$ & تغييرات در بدهىهاى غيرجارى \\
\hline
\end{tabular}


دكتر خواجوى و احمدى فارسانى، بررسى تاثير جنسيت برخثى نمودن مديريت حسابرسى صاحبكار ...

\begin{tabular}{|c|c|c|c|}
\hline $1 \cdot, V T r, \cdot 9 V$ & $1 \cdot, r 99, r \cdot r$ & $1 \cdot, r+1, f q 1$ & جريان وجوه نقد حاصل از فعاليتهاى عملياتى \\
\hline & & & فعاليتهاى سر مايهَذارى \\
\hline$-\Delta 1, r \Delta 9$ & r,ATQ & $-\wedge १, \& \Delta \Delta$ & تغييرات در اوراق بههادار \\
\hline$-r, \cdot \mid V, \wedge \wedge \Delta$ & $-r, P Q, \cdot r q$ & $-r, \cdot \Delta, \Delta r r$ & خالص خريد (فروش) از اموال، ماشينآلات و تجهيزات \\
\hline \multirow[t]{2}{*}{$-t, \cdot 99$, TFF } & $-r, \cdot Y \mid, r \cdot 1$ & $-r, \cdot 9 \Delta, 1 \wedge \vee$ & جريان وجوه نقد حاصل از فعاليتهاى سرمايهَذارى \\
\hline & & & فعاليتهاى تامين مالى \\
\hline$-\Lambda, r \uparrow \Lambda$ & $-1 \Lambda, \Delta 9 \Delta$ & $-11,991$ & خالص افزايش (كاهش) در اسناد يرداختنى بلندمدت \\
\hline$-4 \Delta, V Y q$ & rV,gTe & $-\Lambda १, \Delta \Delta T$ & خالص افزايش (كاهش) در اسناد يرداختنى كوتامدت \\
\hline- & - & - & انتشار (بازخريد) سهام سرمايه \\
\hline$-\Lambda, 1 r \cdot, 1 \vee \cdot$ & $-\Lambda, r \uparrow q, \Gamma \cdot \varphi$ & $-\Lambda, r \cdot 1, r 9 \Lambda$ & سود سهام نقدى يرداخت شده \\
\hline$-\Lambda, \mid \Lambda \uparrow, Y \mu V$ & $-\Lambda, r) \cdot, r \vee G$ & $-\Lambda, r \cdot r, q \uparrow \vee$ & جريان وجوه نقد حاصل از فعاليتهاى تامين مالى \\
\hline $499,81 \mathrm{~V}$ & FV,ATD & $-\Delta \xi, \phi \& r$ & خالص كردش وجوه نقد \\
\hline$\wedge, 1 \Delta 9, \wedge \cdot \wedge$ & 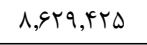 & $\Lambda, \varnothing \vee V, r \Delta \cdot$ & مانده وجه نقد ابتداى دوره \\
\hline$\Lambda, \&$, \&ra & $\Lambda, \& \vee \vee, r \Delta \cdot$ & $\Lambda, \xi Y \cdot, 9 \cdot V$ & مانده وجه نقد يايان دوره \\
\hline
\end{tabular}

بررسى تحليلى مربوط به اوراق بجهادار قابل معامله

\begin{tabular}{|c|c|c|c|}
\hline حسابر سى شده دو سال & حسابرسى شده سال & سال جارى حسابرسى & \\
\hline 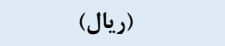 & 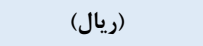 & 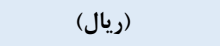 & \\
\hline$r, 194,1 V$. & $T, 19 \cdot, Y F T$ & r,Yץq,११V & اوراق بهادار \\
\hline \% & \% & \%.r.tr & اوراق بهادار به كل دارايىها \\
\hline$\% .4 .9 \Delta$ & $\%$ & $\%$ \%.v^ & اوراق بهادار به دارايىهاى \\
\hline & & \multicolumn{2}{|c|}{ تفكيك و فروش اوراق بهادار از نظر نوع } \\
\hline & & \multicolumn{2}{|r|}{ بر اساس بهاى تمام شده } \\
\hline $1, r \wedge F, q \Delta \&$ & $1, r \wedge \Lambda, r \mid r$ & $1, \Upsilon 9 \wedge, \vee 99$ & الف الف \\
\hline$\Delta r q, \Delta T_{1}$ & $\Delta \Psi \Lambda, \uparrow \wedge \Delta$ & $\Delta \& q, r \cdot$. & ب \\
\hline$r \nvdash r, r \cdot \varphi$ & rrr,fyi & $M F \cdot, \Delta \cdot 1$ & ج \\
\hline r,IDV,Vqr & $r, \mid \varepsilon \cdot, r \varepsilon \wedge$ & $\uparrow, \backslash \wedge \Lambda, \Delta \cdots$ & 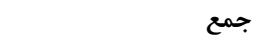 \\
\hline & & \multicolumn{2}{|r|}{ بر اساس ارزش بازار } \\
\hline $1, r \mid \Lambda, r \cdot 1$ & $1, r \wedge 9, r \backslash f$ & $1, r r r, V G \Delta$ & الف الف \\
\hline$\Delta \cdot \Lambda, r \Delta \Lambda$ & $\Delta F G, F \mid f$ & $\Delta \Delta,, \Lambda \mid F$ & ب \\
\hline rrv,gIr & MTY,GIF & rG4,Y19 & ج \\
\hline$r, \mid \varepsilon \uparrow, I V$. & $T, 19 \cdot$, TYT & r, r₹q,११V & 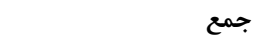 \\
\hline
\end{tabular}


دوفصلنامه حسابدارى ارزشى و رفتارى، سال ششم، شماره يازدهم، بهار و تابستان +. عا

\begin{tabular}{|c|c|c|c|}
\hline \multicolumn{4}{|c|}{ بررسى تحليلى مربوط به حسابهاى دريافتنىى } \\
\hline حسابرسى شده دو سال قبل & سابل قبل شده & سابرسى نشده & \\
\hline (ريال) & 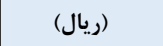 & 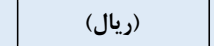 & \\
\hline V.Ir & V.IT & $v \cdot \cdot \Lambda$ & نسبت كردش حسابهاى دريافتنى \\
\hline DI.T. & DI.TV & $\Delta 1 . \Delta T$ & ميانكَين دوره وصول مطالبات \\
\hline (1, & $1,419, \cdot 4 q$ & $1, r+\Delta, \Delta \backslash \Delta$ & هزينه مطالبات مشكوى الوصول \\
\hline$\% \cdot v 9$ & $\% \cdot v \Delta$ & $\% \cdot v V$ & به عنوان درصدى از فروش خالص \\
\hline$\% . \Delta . Y^{c}$ & $\%$ \%.us & $\% .0 .48$ & به عنوان درصدى از خالص دريافتنى \\
\hline 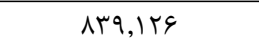 & $\Lambda F \Delta, r \vee F$ & $\Lambda I V, r \pi \Delta$ & هزينه بدهى هاى لاوصول \\
\hline$\% \cdot \varphi \wedge$ & $\% \cdot \varphi \wedge$ & $\% \cdot Y V$ & به عنوان درصدى از فروش خالص \\
\hline \%.K.KT & $\%$ & \%.r.T & به عنوان درصدى از حسابهاى دريافتنى خالص \\
\hline \multicolumn{4}{|c|}{ تجزيه و تحليل سنى حسابهاى دريافتنى (همه فروشها اعتبارى با خالص · ب روز هستند.) } \\
\hline 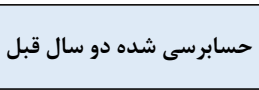 & حسابرسى شده & | سال جارى حسابرسى & \\
\hline \multirow[t]{2}{*}{ 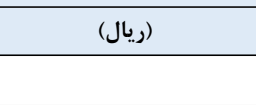 } & (ريال) & (ريال) & \\
\hline & & \multicolumn{2}{|r|}{ ميانگين روزهاى وصول مطالبات فروش نسيه } \\
\hline IY,YYQ,YK. & $I T, Y Y \Lambda, \Lambda F H$ & $\mid r, F 4 \cdot, r \& q$ & روز •r- \\
\hline$\Lambda, V I T, Y \Lambda T$ & $\Lambda, V F \cdot,|V|$ & $\wedge, \vee 99,1 \wedge \uparrow$ & روز • \\
\hline r,TrT,GT. & $r, 1 \Lambda \cdot, \cdot V \uparrow$ & 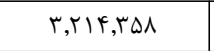 & روز •91-9 \\
\hline $1, \Delta \wedge 9, \mathrm{rFT}$ & $1, \Delta \wedge r, 994$ & $1, \Delta \Delta T, g r q$ & بيش از • · روز \\
\hline$r \Delta, \Lambda \Lambda \cdot, \Delta q Y$ & $r \Delta, q \Psi ı, \vee \wedge \cdot$ & $r \varepsilon, \cdots \varphi, r q \uparrow$ & جمع حسابهاى دريافتنى \\
\hline - & $-1,419, \cdot 49$ & $-1, r F \Delta, \Delta \backslash \Delta$ & زيان ناشى از مطالبات مشكول الوصول \\
\hline$T F, \Delta \Delta \Delta, Y G Y$ & $T Y, 94 \cdot, 9 Y G$ & TY,94.,qTG & خالص حسابهاى دريافتنى \\
\hline
\end{tabular}

بررسى تحليلى مربوط به موجودى كالا (FIFO)

\begin{tabular}{|c|c|c|c|}
\hline حسابرسى شده دو سال & حسابرسى شده سال & سال جارى حسابرسى & \\
\hline 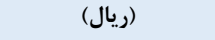 & 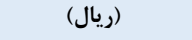 & 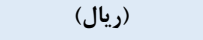 & \\
\hline$r F, T \cdot T, \Delta r T$ & $T F, r G D, F F A$ & $r F, V \Delta \Lambda, V \wedge F$ & سرمايه در كردش \\
\hline 1.99 & 1.99 & 1.71 & نسبت جارى \\
\hline $1 . \cdot 1$ & $1 . \cdot 1$ & $1 . \cdot r$ & 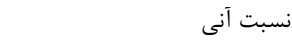 \\
\hline Q.VG & Q.VG & Q.VF & كردش موجودى \\
\hline $94 . r \Delta$ & GT.MT & $q T . \Delta V$ & ميانكَين دوره گردش موجودىها \\
\hline 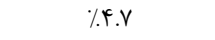 & $\% \leftarrow \cdot v$ & $\% \uparrow . \wedge$ & ل ميه فروش به سود \\
\hline
\end{tabular}


دكتر خواجوى و احمدى فارسانى، بررسى تاثير جنسيت برخثى نمودن مديريت حسابرسى صاحبكار ... وبس

\begin{tabular}{|c|c|c|c|}
\hline$\% 1 \% . V$ & $\% 1 \% .1$ & $\% 1 \%$ & سود قبل از ماليات / كل دارايىها \\
\hline$\%$ \%५. & $\%$ \%.T & $\%$ \%.. & سرمايه در گردش / كل دارايىها \\
\hline 1.11 & 1.11 & 1.11 & فروش خالص / كل دارايىها \\
\hline V.rT & v.19 & $v . \cdot 4$ & فروش خالص / سرمايه در كردش \\
\hline \multirow[t]{2}{*}{ r.11 } & r.AT & r.11 & فروش خالص/ هزينههاى ادارى و فروش \\
\hline & & \multicolumn{2}{|c|}{ تفكيك موجودى ها بر اساس نوع موجودى } \\
\hline $4,19 \cdot, \cdot 94$ & $f .19 \vee, \mid 01$ & $\uparrow, \backslash \wedge \Delta, \cdot \vee \Delta$ & 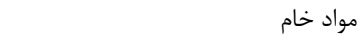 \\
\hline$\Delta, \vee \uparrow \Delta, १ \wedge \varphi$ & D,VYT, YYY & $0, \vee G \Psi, 1 \cdot 9$ & كار در جريان ساخت \\
\hline $11, \wedge \cdot \Delta, \varphi \cdot \varphi$ & $\|, \wedge \backslash \vee, \vee \Delta \varphi$ & $11, \wedge \varphi 9, \vee १ \diamond$ & كالاى ساخته شده \\
\hline$r \mid, V \uparrow 1,9 \wedge V$ & $r|, V \notin V, r \Delta|$ & $r|, \wedge| f, q \vee q$ & جمع \\
\hline
\end{tabular}

جداول بهاى تمام شده كالاى توليد شده و كالاى فروش رفته

جدول بهاى تمام شده كالاي توليد شده

\begin{tabular}{|c|c|c|c|}
\hline حسابرسى شده دو & سابر قبى شده & حسابرسى نشده & \\
\hline \multirow[t]{2}{*}{ 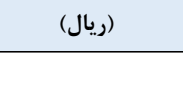 } & 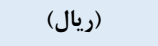 & 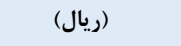 & \\
\hline & & \multicolumn{2}{|r|}{ هزينه مواد مستقيم } \\
\hline$F, Y V F, f \backslash 9$ & $4,19 \cdot, \cdot 94$ & $f,|q \vee,| \Delta \mid$ & موجودى مواد ابتداى دوره \\
\hline$\vee \wedge, \vee G \cdot, \vee \vee \vee$ & $\vee \wedge, \vee \vee \vee, \cdot \vee q$ & $\vee \wedge, \vee r q, 9 \Delta q$ & خريد مواد مستقيم \\
\hline$\Lambda r, \cdot r \Delta, 199$ & $\wedge r, q \hookrightarrow q, \mid$ FQ & $\Lambda r, 9 r \varepsilon, \Lambda 1$. & هزينه مواد مستقيم در دسترس \\
\hline$-4,19 \cdot, \cdot 99$ & $-F,|9 \vee,| \Delta \mid$ & $-F, \backslash \wedge \Delta, \cdot \vee \Delta$ & كسر مىشود: موجودى مواد انتهاى دوره \\
\hline$\vee \wedge, \wedge f \Delta, 1 \ldots$ & $\vee \wedge, \vee \vee ।, १ ९ ४$ & $V \wedge, V \uparrow I, V \Psi \varepsilon$ & هزينه مواد مستقيم \\
\hline$T, F \cdot V, \Lambda T T$ & $r\}, F \& \mid, \Lambda T 1$ & $r T, F \Delta \Lambda, T \cdot G$ & هزينه دستمزد مستقيم \\
\hline$r F, \wedge F, r V G$ & $r F, \| \wedge, \Delta K_{G}$ & $r F, \mid r \varepsilon, q \cdots$ & هزينه سربار توليد \\
\hline $\mid r \Delta, r r V, r \cdot \Lambda$ & $|r \Delta, r \Delta r, r \varepsilon|$ & $\left|r \Delta, r r_{G, \Lambda}\right|$ & هزينه توليد تحميل شده \\
\hline$\Delta, \vee \backslash \Lambda, \uparrow \& \varphi$ & $\Delta, \vee \uparrow \Delta, ৭ \wedge \varepsilon$ & $\Delta, V M T, r \in F$ & اضافه مىشود: كار در جريان ابتداى دوره \\
\hline$|r|, \cdot \Delta \Delta, \& \vee r$ & $|r|, \cdot 9 \Lambda, r \notin V$ & $|r|, \cdot 99,1 \wedge \Delta$ & مجموع هزينههاى توليد \\
\hline$-\Delta, \vee \vee \Delta \Delta, q \wedge \varepsilon$ & $-Q, V H T, T Y F$ & $-\Delta, \vee G \Psi, 1 \cdot \varphi$ & كسر مىشود: كار در جريان پِايان دوره \\
\hline \multirow[t]{2}{*}{$1 r \Delta, r \cdot ৭, \varsigma \Lambda \Lambda$} & $\mid r \Delta, r \varphi q, \cdot r$ & $\mid r \Delta, r \cdot \varphi, \cdot v \wedge$ & بهاى تمام شده كالاى توليد شده \\
\hline & & \multicolumn{2}{|r|}{ جدول بهاى تمام شده كالاى فروش رفته } \\
\hline $11, \vee \Delta \varphi, 19 \Lambda$ & $11, \lambda \cdot \Delta, \varepsilon \cdot \varphi$ & $\|, \wedge I \vee, \vee \Delta \varphi$ & موجودى كالاى ساخته شده ابتداى دوره \\
\hline $\mid r \Delta, r \cdot ৭, \varsigma \wedge \Lambda$ & $\mid r \Delta, r \varphi \varphi, . . r$ & $1 r \Delta, r \cdot \varphi, \cdot v \Lambda$ & اضافه مىشود: بهاى تمام شده كالاى توليد شده \\
\hline
\end{tabular}


دوفصلنامه حسابدارى ارزشى و رفتارى، سال ششم، شماره يازدهم، بهار و تابستان +. عا

r.

\begin{tabular}{|c|c|c|c|}
\hline $1 \% \nabla, \cdot 9 \Delta, \wedge \Delta \Delta$ & $|r v| V \mid,, \varphi \cdot \Lambda$ & $I r v, I r r, \Lambda r F$ & بهاى كالاى آماده براى فروش \\
\hline$-11, \Lambda \cdot \Delta, \varphi \cdot \varphi$ & $-\| I, \Lambda \backslash \vee, V \Delta S$ & $-11, \wedge \varsigma 9, \vee 9 \Delta$ & دوره مسى شود: موجودى كالاى ساخته شده انتهاى \\
\hline$I r \Delta, r \varphi \cdot, r F q$ & $1 T \Delta, r \Delta H, \wedge \Delta T$ & $\mid r \Delta, r \Delta V, \cdot r \cdot$ & بهاى تمام شده كالاى فروش رفته \\
\hline
\end{tabular}

بررسى تحليلى مربوط به ييش يرداخت هزينهها

\begin{tabular}{|c|c|c|c|}
\hline حسابرسى شده دو سال قبل & | حسابرسى شده سال قبل | & سال جارى حسابرسى نشده & \\
\hline (ريال) & (ريال) & (ريال) & \\
\hline T,TH,IGV & T,rT৭,VAr & T,YT\&,qVq & ي ي يش يرداخت هزينهها \\
\hline$\%$ \%.ve & $\%$ \%.AV & $\%$ \%.VF & درصد دارايىهاى جارى \\
\hline \multirow[t]{2}{*}{$\%$ \%.Y. } & $\%$ \%.FV & $\%$ \%.Y. & درصد مجموع دارايىها \\
\hline & & \multicolumn{2}{|c|}{ تفكيك بِيش يرداخت هزينهها } \\
\hline $1, \cdot|\Delta, \Delta 9|$ & $1, \cdot \varphi \cdot, \Delta \cdot q$ & $1, \cdot|f, \cdot| f$ & يِيش پِرداخت اجاره \\
\hline $9 \mid V, 910$ & $\varepsilon \notin V, \wedge \varphi$ & GMT,YTG & يِيش يرداخت بيمه \\
\hline$\Delta ৭ ৭, १ ९$. & GIr,IAV & $\Delta \Lambda \cdot, V r$. & تجهيزات ادارى \\
\hline T,YTH,ISV & 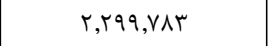 & T,YT\&,qVq & جمع - اع \\
\hline
\end{tabular}

بررسى تحليلى مربوط به اموال، ماشين آلات و تجهيزات

\begin{tabular}{|c|c|c|c|}
\hline حسابر سى شده دو سال قبل & حسابر سى شده سال قبل & سال جارى حسابرسى نشده & \\
\hline \multirow[t]{2}{*}{ 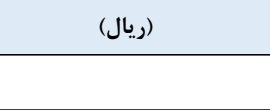 } & (ريال) & (ريال) & \\
\hline & & \multicolumn{2}{|c|}{ بهاى تمام شده اموال و تجهيزات برحسب نوع } \\
\hline $1, \Delta \& Y, \mid F r$ & $1, \Delta \& Y, I F r$ & $1, \Delta \& Y, \mid F T$ & 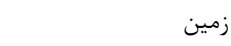 \\
\hline $11, \Delta 91, \cdot \Delta \cdot$ & $11, \Delta V \cdot, r V V$ & $11, \Delta 99,4 \cdot \wedge$ & ساختمان \\
\hline IF,rrV,FFF & $\mid F, \Delta \& r, \Lambda F \Delta$ & $\mid f, V \uparrow \wedge, \cdot V r$ & ماشينآلات و تجهيزات \\
\hline$r, \uparrow q я, \cdot V \Delta$ & r,זAr,AVV & 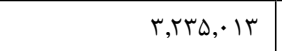 & اثاثه و منصوبات \\
\hline FQT,T.V & $F \Delta V, f q F$ & $|49| 9 \mid$, & بهسازى اموال استيجارى \\
\hline $999,4 T \Delta$ & $99 \wedge, \wedge r \Delta$ & $s \mathrm{qVI}, V \cdot r$ & تجهيزات تحويلى \\
\hline rT,1., , MFF & $r T, Y \cdot D, F V I$ & rr, rFV,, $9 q 9$ & 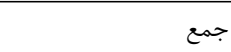 \\
\hline
\end{tabular}

اموال، ماشين آلات و تجهيزات اضافه شده برحسب نوع

\begin{tabular}{|c|c|c|c|}
\hline - & - & - & زمين \\
\hline$\Delta \cdot r, F \cdot F$ & $\forall \wedge \xi, \Delta \& \mid$ & FqT,AVT & ساختمان \\
\hline $1, \cdot 19, \mathrm{~V} \mid \mathrm{r}$ & $1, \cdot \Delta V, \Delta 11$ & $1, \cdot r G, Y Y Y$ & ماشينآلات و تجهيزات \\
\hline rV৭,DAr & rVA,VAI & $r \varepsilon V, \cdots v$ & اثاثه و منصوبات \\
\hline
\end{tabular}



دكتر خواجوى و احمدى فارسانى، بررسى تاثير جنسيت برخنى نمودن مديريت حسابرسى صاحبكار ...

\begin{tabular}{|c|c|c|c|}
\hline$r \cdot, \uparrow \wedge q$ & 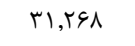 & ri, fq. & بهسازى اموال استيجارى \\
\hline$\Lambda \vee, 991$ & $q \cdot, q \uparrow q$ & $\wedge \vee, १ ९ १$ & تجهيزات تحويلى \\
\hline$r, \cdot I V, \wedge \wedge \Delta$ & $r, \cdot r \Delta, \cdot r q$ & $r, \cdots \Delta, \Delta r r$ & جمع \\
\hline
\end{tabular}

اموال، ماشين آلات و تجهيزات كنار كذاشته شده برحسب نوع

\begin{tabular}{|c|c|c|c|}
\hline- & - & - & زمين \\
\hline 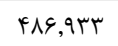 & $\Delta \cdot V, r \mu r$ & $F q r, \Delta F I$ & ساختمان \\
\hline$\Lambda r \cdot, r Y \Lambda$ & $\Delta \mu 1,11$. & $\wedge 41,99 \mathrm{~V}$ & ماشينآلات و تجهيزات \\
\hline fqf,Fr. & $\uparrow q 1,90$. & $\Delta|F, A V|$ & اثاثه و منصوبات \\
\hline$r V, V r \cdot$ & $r \varepsilon, 9 \Lambda$. & rV,Vqf & بهسازى اموال استيجارى \\
\hline$M, F Y$. & $\Lambda \Lambda, \Delta T_{q}$ & $\Lambda \Delta, 1 \cdot r$ & تجهيزات تحويلى \\
\hline $1,91 \vee, \wedge 91$ & $1, q 4 \Delta, q \cdot r$ & $1,99 r, r \cdot 4$ & جمع \\
\hline
\end{tabular}

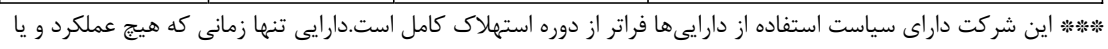

ارزش اسقاطى نداشته باشندكنار كذاشته مى شود.

بررسى تحليلى مربوط به استههلاك انباشته

\begin{tabular}{|c|c|c|c|}
\hline حسابرسى شده & شده سال قبل & حسابرسى نشده & \\
\hline \multirow[t]{2}{*}{ (ريال) } & (ريال) & (ريال) & \\
\hline & & \multicolumn{2}{|r|}{ ستهلاك انباشته دارايىها از نظر نوع } \\
\hline- & - & - & زمين \\
\hline $1, \Lambda \cdot \vee, \cdot 9 \vee$ & $1, \wedge \vee r, \vee q$. & $1,909,991$ & ساختمان \\
\hline$r, r r \cdot, V \cdot F$ & $r, f \Delta D \mid \cdot \cdot \Delta I$ & 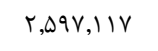 & ماشينآلات و تجهيزات \\
\hline 997,499 & VIF,gYs & $V \cdot 9,9 \curlyvee 9$ & اثاثه و منصوبات \\
\hline Vr,q६. & VV,GYF & $\Lambda \cdot, \cdot 9 r$ & بهسازى اموال استيجارى \\
\hline QY,DTD & QT,VG & 91, TFF & تجهيزات تحويلى \\
\hline \multirow[t]{2}{*}{$\Delta, \cdot \cdot \varphi, V \Delta r$} & $\Delta, r \cdot 9, \wedge \Delta r$ & $\Delta, F r \Delta, \cdot V r$ & جمع \\
\hline & & \multicolumn{2}{|r|}{ *****: استهلاك به وسيلهى انواع دارايى } \\
\hline- & - & - & 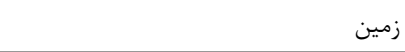 \\
\hline$\Delta \Delta F, \cdot \varphi V$ & $\Delta V \Psi, \cdot \Gamma Q$ & DVY,FFT & ساختمان \\
\hline $9 \Delta \cdot \Delta T)$ & $q \Delta 1, f \Delta V$ & $911, \cdot 94$ & ماشينآلات و تجهيزات \\
\hline$\uparrow q \xi, f \cdot \varphi$ & $\Delta \cdot 9,11$. & $\Delta 1 \cdot, \mid V F$ & اثاثه و منصوبات \\
\hline$r \cdot, \cdot r \varepsilon$ & $r \cdot, q \uparrow \xi$ & $r \cdot, r \& 1$ & بهسازى اموال استيجارى \\
\hline$\wedge f, 819$ & $\Lambda F, V \in V$ & $\Lambda T, \Delta \wedge r$ & تجهيزات تحويلى \\
\hline
\end{tabular}


دوفصلنامه حسابدارى ارزشى و رفتارى، سال ششم، شماره يازدهم، بهار و تابستان +. عا

\begin{tabular}{|c|c|c|c|}
\hline$r, 11 \Delta, \xi 4 \Delta$ & $r, \mid f q, \cdots r$ & $r, \mid \Lambda \Lambda, \Delta Y r$ & جمع \\
\hline$\% .9 .09$ & $\% .9 .9 \mathrm{~V}$ & $\%$ \%.rq & استهلاكى به عنوان درصدى از اموال، ماشين آلات و تجهيزات \\
\hline
\end{tabular}

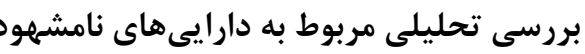

\begin{tabular}{|c|c|c|c|}
\hline حسابرسى شده دو سال قبل & حسابرسى شده سال قبل & سال جارى حسابرسى نشده & \\
\hline $1, \lambda \Lambda \cdot, 1 \cdot 4$ & 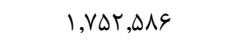 & $1, I \vee \Delta, \cdot \bullet r$ & دارايى هاى نامشهود \\
\hline \multirow[t]{2}{*}{$\% \cdot r \cdot r$} & $\% 1.11$ & $\%$ \%.rs & 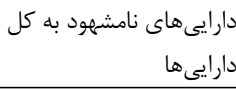 \\
\hline & & \multicolumn{2}{|c|}{ تفكيك دارايى هاى نامشهود } \\
\hline$\wedge \triangle ৭, q \vee \Delta$ & $\wedge \triangle ৭, q \vee \Delta$ & $\Lambda \Delta १, q \vee \Delta$ & 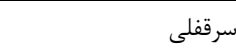 \\
\hline $1, \cdot r \cdot, \mid r \Lambda$ & $\wedge 9 \%, 911$ & VबQ, & 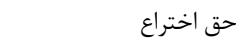 \\
\hline \multirow[t]{2}{*}{$1, \Lambda \Lambda \cdot, 1 \cdot f$} & $1, \vee \Delta Y, \Delta \wedge \varphi$ & $1,9 r \Delta, \cdot 99$ & جمع \\
\hline & & \multicolumn{2}{|c|}{ مالكيتهاى نامشهود (كاهش ارزش / بهسازى) } \\
\hline- & - & - & 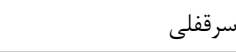 \\
\hline- & - & - & 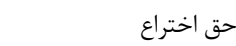 \\
\hline \multirow[t]{2}{*}{-} & - & - & جمع \\
\hline & & \multicolumn{2}{|c|}{ استهلاك دارايى هاى نامشهود } \\
\hline- & - & $\cdot$ & 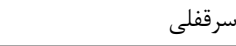 \\
\hline$|r V, \Delta| \Lambda$ & $|r V, D| \Lambda$ & $|r V, \Delta| \Lambda$ & 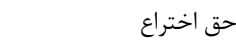 \\
\hline$|r V, \Delta| \Lambda$ & $|r V, \Delta| \Lambda$ & $|r V, D| \Lambda$ & جمع \\
\hline
\end{tabular}

\section{بررسى تحليلى مربوط به ساير دارايى هاى غيرجارى}

\begin{tabular}{|c|c|c|c|}
\hline حسابرسى شده دو سال & حسابرسى شده سال & 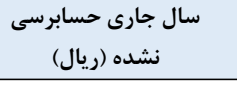 & \\
\hline$\varphi, \Lambda F T, \cdot \Delta q$ & $F, ৭ \uparrow \xi, \Gamma \& V$ & $\uparrow, १ \Delta \Delta, १ \curlyvee \wedge$ & ساير دارايىهاى غيرجارى \\
\hline \multirow[t]{2}{*}{$\%$.Q.T. } & $\% .0 .19$ & $\%$ & 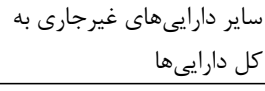 \\
\hline & & \multicolumn{2}{|c|}{ تفكيك ساير دارايىهاى غيرجارى } \\
\hline $1, Y T H, \Delta Y 1$ & 1, YYF, YVq & $1, r V \cdot, r \notin \varepsilon$ & سيرده براى موسسات رفاهى \\
\hline T,FVT,FYA & $r, \Delta \Delta \varphi, \vee \cdots$ & $r, D I V, r T V$ & اسناد دريافتنى \\
\hline $1, \cdot \varphi v, \cdot \wedge v$ & $1, \cdot r \Delta, r \wedge \Lambda$ & $1, \cdot 9 \Lambda, r F F$ & ساير دارايىهاى غيرجارى \\
\hline$f, \Lambda \uparrow t, \cdot \Delta \varphi$ & $\uparrow, १ \uparrow \&, \Gamma \& V$ & $\uparrow, १ \Delta \Delta, q \curlyvee \wedge$ & 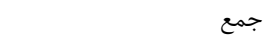 \\
\hline
\end{tabular}




\begin{tabular}{|c|c|c|c|c|}
\hline \multicolumn{5}{|c|}{ بررسى تحليلى مربوط به خر يد، يرداختنى ها و ماليات } \\
\hline 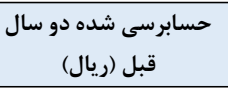 & \multicolumn{2}{|c|}{ حسابرسى شده سال قبل } & \multirow[t]{2}{*}{ 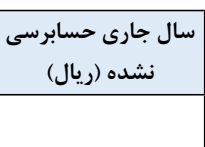 } & \\
\hline & & & & 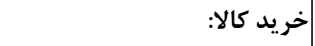 \\
\hline \multirow[t]{2}{*}{$\vee \wedge, \vee \varphi \cdot, \vee V \vee$} & \multicolumn{2}{|c|}{$V \wedge, V r q, \cdot \vee q$} & $\vee \wedge, \vee Y q, ९ \Delta ৭$ & |خريد مواد اوليه \\
\hline & & & \multicolumn{2}{|c|}{ خريد براى ماه قبل و پِ از بايان دوره } \\
\hline$१, \Delta १ ৭, \uparrow \cdot ५$ & \multicolumn{2}{|c|}{ 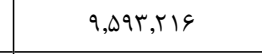 } & $৭, \Delta \varphi \cdot, \cdots \Delta$ & Xريد براى اسفند • XIr X \\
\hline$V, \cdot r q, \cdot V \Delta$ & \multicolumn{2}{|c|}{$\checkmark, \cdot \wedge r, V Y \Delta$} & $V, 1 \cdot 1, r \mu r$ & 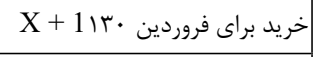 \\
\hline$q \uparrow \Delta, 1 Y q$ & \multicolumn{2}{|c|}{$q \uparrow \Delta, r<q$} & qFF,VDG & بركشت از خريد و تخفيفات \\
\hline$\%$ \%. & \multicolumn{2}{|c|}{$\%$ \%.r. } & $\%$ \%.r. & |به عنوان درصدى از خريد \\
\hline $\mid f, \cdot r \Lambda, f \cdot \varphi$ & \multicolumn{2}{|c|}{$14, \cdot 1 \wedge, q \cdot 1$} & $|f, \cdot 9 \vee, 9| \wedge$ & | حسابهاى يرداختنى \\
\hline$\% \cdot 1.4$ & \multicolumn{2}{|c|}{$\%$} & $\% \cdot \mathrm{A} \cdot \mathrm{V}$ & ] به عنوان درصدى از فروش خالص \\
\hline \multicolumn{5}{|c|}{ مانده حسابهاى يرداختنى براى ماه قبل و بعد يا يان دوره } \\
\hline $\mid f, \cdot r \Lambda, \uparrow \cdot \varphi$ & $14, \cdot 1 \wedge, q \cdot 1$ & $|f, \cdot 9 \vee, 9| \wedge$ & \multicolumn{2}{|c|}{ 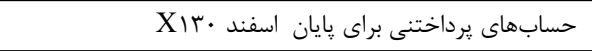 } \\
\hline $\mid 4, \cdot r r, \cdot q 1$ & $I F, \cdot V V, \cdot T Q$ & $|f, \cdot| \cdot, \Delta \Delta F$ & \multicolumn{2}{|c|}{ 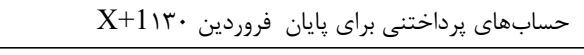 } \\
\hline$\Lambda \cdots, r \varepsilon$. & $\Lambda \backslash V, \xi 4 \mathrm{Y}$ & $\vee \wedge \Lambda, F \vee F$ & & بدهى مالياتى \\
\hline$\% 1.99$ & \%TY.FY & $\% 1.90$ & & درصد از هزينههاى مالياتى \\
\hline
\end{tabular}

بررسى تحليلى مربوط به ساير بدهى هاى جارى

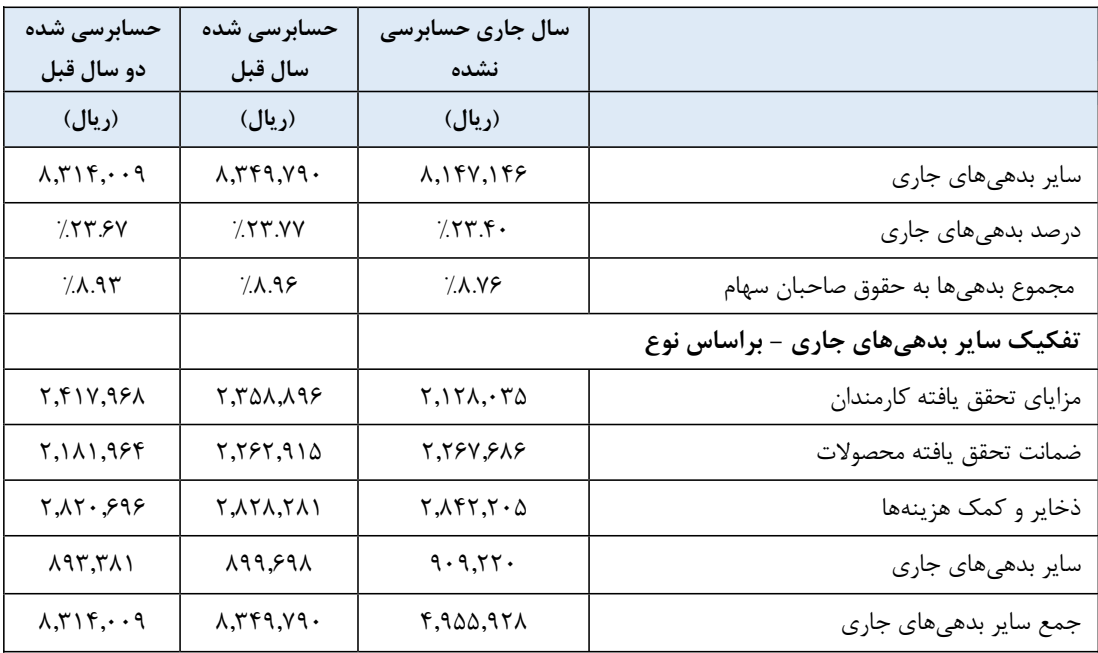


دوفصلنامه حسابدارى ارزشى و رفتارى، سال ششم، شماره يازدهم، بهار و تابستان +. عا

\begin{tabular}{|c|c|c|c|c|c|c|}
\hline \multicolumn{7}{|c|}{ بررسى تحليلى مربوط به بدهىها } \\
\hline \multicolumn{2}{|c|}{$\begin{array}{c}\text { حسابرسى شده دو سال } \\
\text { حبل (ريال) }\end{array}$} & \multicolumn{2}{|c|}{ 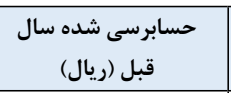 } & \multicolumn{2}{|c|}{ 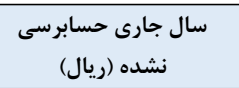 } & \\
\hline \multicolumn{2}{|c|}{$11, \Delta \cdot r, \uparrow \wedge 9$} & \multicolumn{2}{|r|}{$11, \Delta F \Delta, r \Delta F$} & \multicolumn{2}{|r|}{$11,9 \cdot 9, \cdot 1 r$} & بدهى بلندمدت \\
\hline \multicolumn{2}{|r|}{$\%$ \%Y.F } & \multicolumn{2}{|r|}{$\%$ TV.D } & \multicolumn{2}{|r|}{$\%$ \% V.D } & سدهام بلندمدت به حقوق صاحبان \\
\hline \multicolumn{2}{|r|}{$\%$ \%r.r } & & $\%$ Ir.F & \multicolumn{2}{|r|}{$\% 1 \% . \Delta$} & 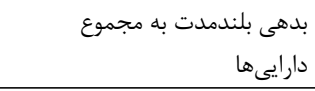 \\
\hline \multicolumn{2}{|c|}{$9 \Delta T, r \& V$} & & qVG, F\& & & $9 \Delta r, \cdot \vee 1$ & هزينه بهره \\
\hline \multicolumn{2}{|r|}{$\% .9 .0$} & & $\% .9 .9$ & & $\% .9 .0$ & هزينه بهره به كل بدهى \\
\hline \multirow{2}{*}{\multicolumn{2}{|c|}{$\Lambda, \vee \Delta 1, \cdot 9 \Lambda$}} & & $\Lambda, Y \Lambda \Lambda, Y Y F$ & & $\wedge, \varnothing 99,1 \vee r$ & اسناد يرداختنى كوتاهمدت \\
\hline & & & & \multicolumn{3}{|r|}{ تفكيك بدهى هاى بلندمدت } \\
\hline \multicolumn{2}{|c|}{$f, q \cdot r, \Delta \mid \uparrow$} & & $r, \wedge f \Delta, r \vee \backslash$ & & $f, q r r, \cdot r V$ & رهن يرداختنى \\
\hline \multicolumn{2}{|c|}{$r, \varphi \Delta V, \Delta \cdot \Lambda$} & & $r, Y \backslash Q, \vee \varepsilon \mid$ & & $r, \& \vee \wedge, \Lambda \Delta \wedge$ & موافقتنامه اعتباركردان \\
\hline \multicolumn{2}{|c|}{$r, 19 V, 1 \cdot 9$} & & $r, r \backslash \wedge, 991$ & & $r,|\Delta F, F| V$ & اسناد يرداختنى ميانمدت \\
\hline \multicolumn{2}{|c|}{ 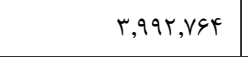 } & & $r, 9 Y r, I V \Lambda$ & & r,१५r,११५ & اسناد برداختنى بلندمدت بانكها \\
\hline \multicolumn{2}{|c|}{$14, V T \cdot, \wedge 94$} & & $\mid \uparrow, V \cdot r, r \cdot 1$ & & $\mid \uparrow, q 9 \cdot, r \cdot r$ & مجموع بدهى مها \\
\hline \multicolumn{2}{|c|}{$-r, r \mid V, r \cdot \varphi$} & \multicolumn{2}{|r|}{$-r, \mid \Delta \xi, q \uparrow V$} & \multicolumn{2}{|r|}{$-r, \wedge 1, r q 1$} & كسرهى مى شود: حصه جارى بلندمدت \\
\hline \multicolumn{2}{|c|}{$11, \Delta \cdot r, \uparrow \wedge q$} & & $11, \Delta F \Delta, r \Delta F$ & & $11,9 \cdot 9, \cdot 1 r$ & مجوع بدهىهاى بلندمدت \\
\hline \multicolumn{7}{|c|}{ بررسى تحليلى مربوط به ساير بدهى هاى غيرجارى } \\
\hline دو دابرسى شده & \multicolumn{2}{|c|}{ سال قبل (ريال) حسابر شده } & \multicolumn{2}{|c|}{ سال جارى حسابرسى (ريال) } & & \\
\hline$F, \Delta r \cdot, F r \Lambda$ & $f, \uparrow$ & 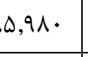 & $\uparrow, r \wedge$ & rזA & & 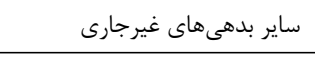 \\
\hline \multirow[t]{2}{*}{ 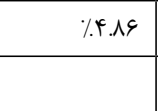 } & \multicolumn{2}{|r|}{$\% .4 . \wedge 1$} & \multicolumn{2}{|c|}{$\% 4.91$} & \multicolumn{2}{|r|}{ جمع بدهى ها به حقوق صاحبان سهام } \\
\hline & & & \multicolumn{4}{|c|}{ تفكيك ساير بدهى هاى غير جارى - بر اساس نوع } \\
\hline $1, r Y V, 1 \Lambda \Lambda$ & $1, r$ & $1, V F F$ & $1, \cdot \cdot$ & $9 \cdot 1$ & & مزاياى تحقق يافته كارمندان \\
\hline $1,9 \Delta r, F 9 \cdot$ & 1,9 & $r, 1 \cdot r$ & 1,94 & , १९s & & ضمانت تحقق يافته محصولات \\
\hline $1, r \Delta \cdot, \vee \vee 1$ & $1, r$ & 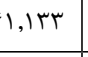 & $1, r \Delta$ & 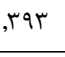 & & 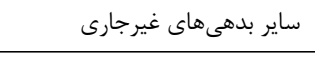 \\
\hline$\uparrow, \Delta r \cdot, r \mu \wedge$ & $f, f$ & $\Delta, ৭ \wedge$ & $\uparrow, r \wedge$ & , r ג & & جمع ساير بدهى هاى غير جارى \\
\hline
\end{tabular}




\begin{tabular}{|c|c|c|c|}
\hline \multicolumn{4}{|c|}{ بررسى تحليلى مربوط به سود انباشته } \\
\hline حسابرسى شده & سال قبل (ريال) & سابرسى نشده & \\
\hline & & & 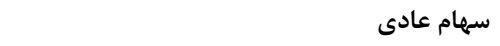 \\
\hline $1 \cdot, \cdots, \cdots$ & $1 \cdot, \cdots, \cdots$ & $1 \cdot, \cdots, \cdots$ & سهام در دست سهامداران \\
\hline$\because \cdot 1$ & $\because \cdot 1$ & $\because \cdot 1$ & ارزش اسمى هر سهمم \\
\hline$\cdot .49$ & $\cdot .49$ &. .49 & صرف سهام (هر سهم) \\
\hline$\cdot . \Delta \cdot$ & $\cdot . \Delta \cdot$ & $\cdot . \Delta \cdot$ & قيمت عرضه اوليه سهام \\
\hline$f \cdot .90$ & +1.10 & $41 . \cdot 1$ & قيمت جارى هر سهمم \\
\hline $1 \cdots, \cdots$ & $1 \cdots, \cdots$ & $1 \cdots, \cdots$ & 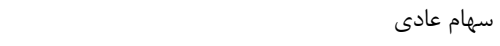 \\
\hline$\uparrow, \wedge \Delta \cdot, \cdots$ & $\uparrow, \wedge \Delta \cdot, \cdots$ & $\uparrow, \wedge \Delta \cdot, \cdots$ & صرف سهام \\
\hline$\uparrow, q \Delta \cdot, \cdots$ & $\uparrow, q \Delta \cdot, \cdots$ & $\uparrow, q \Delta \cdot, \cdots$ & جمع سهام عادى \\
\hline$\cdot .11$ & $\cdot . \Lambda T$ & $\cdot .14$ & سود تقسيمى هر سهمم \\
\hline$\%$. $\cdot \cdot$ & $\%$ & $\%$. . . & سود تقسيمى هر سهم به عنوان درصدى از قيمت سهم \\
\hline$\cdot . \Lambda T$ & $\cdot . \Lambda t$ & $\cdot . \wedge \Delta$ & سود هر سهم \\
\hline \multirow[t]{2}{*}{$\varphi \cdot \varphi, \Delta \cdot \Lambda, \Delta \cdot r$} & $\uparrow \|, \uparrow \varphi \Delta, r\}$. & $\varphi_{1} \cdot, \cdot \bullet 9, \wedge \vee V$ & ارزش بازار كل سرمايه شركت \\
\hline & & & صورت سود انباشته \\
\hline 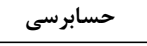 & 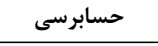 & 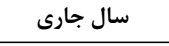 & \\
\hline 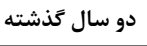 & سال كذشته & حسابرسى نشده & \\
\hline rद, $901, \vee r 4$ & $r v, \cdot \varphi \mid, r \Delta \varphi$ & $r \vee, \cdot \Delta \Lambda, \Delta \wedge F$ & سود انباشته ابتداى دوره \\
\hline$\Lambda, r / 9, \vee 9$. & 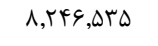 & $\Lambda, F \Delta F, q \Lambda 1$ & سود خالص \\
\hline$F \Delta,|V|, \Delta T G$ & $\vee \Delta,\ulcorner\wedge \vee, \wedge q 1$ & $\uparrow \Delta, \Delta \mid r, \Delta \& \Delta$ & جمع سود انباشته \\
\hline$-\Lambda,|r \cdot,| \vee \cdot$ & $-\Lambda, Y \uparrow ৭, \Gamma \cdot \varphi$ & $-\Lambda, r \cdot 1, r 9 \Lambda$ & كسر مىشود سود سهام يرداختى \\
\hline$r \vee, \cdot F l, r \Delta \varphi$ & $r V, \cdot \Delta \Lambda, \Delta \Lambda \uparrow$ & $r V, r|r| ,9 \Lambda$ & سود انباشته انتهاى دوره \\
\hline
\end{tabular}


دوفصلنامه حسابدارى ارزشى و رفتارى، سال ششم، شماره يازدهم، بهار و تابستان +. عا

\begin{tabular}{|c|c|c|c|}
\hline \multicolumn{4}{|c|}{ بررسى تحليلى مربوط به فروشها } \\
\hline حسابر سى شده دو سال قبل & | حسابر سى شده سال قبل & سال جارى حسابرسى نشده & \\
\hline \multirow[t]{2}{*}{ (ريال) } & 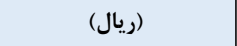 & 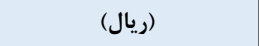 & \\
\hline & & \multicolumn{2}{|r|}{ فروش محصولات } \\
\hline $91,999, \nvdash \vee ध$ & $94, \cdot 91,449$ & $91,|k \cdot, \lambda \mu|$ & محصول الف \\
\hline rF,ATr,rqF & MF,FVD, IG. & $r F, \wedge r r, r q F$ & | محصول ب \\
\hline$\Delta 1, \vee \wedge \wedge, \& \mathrm{VV}$ & $\Delta T, r \cdot G, \Delta T Y$ & $\Delta T, r H T, g V V$ & 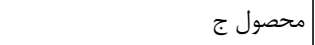 \\
\hline \multirow[t]{2}{*}{$|\vee \wedge, \Delta \Lambda|, \Delta \cdot \Lambda$} & 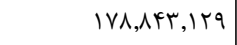 & $\mid V \wedge, r q ৭, q \cdot r$ & 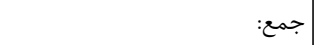 \\
\hline & & \multicolumn{2}{|r|}{ تركيب فروشها: } \\
\hline$\% .01 .0$ & $\% \Delta 1 . \Delta$ & $\% .01 .1$ & | محصول الف \\
\hline$\% 19.0$ & $\% 19.4$ & $\% 19.0$ & | محصول ب \\
\hline \multirow[t]{2}{*}{$\%$ \%. } & $\%$ \% . . & $\%$ \%.. & 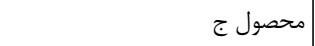 \\
\hline & & \multicolumn{2}{|r|}{ حاشيه ناخالص توسط محصولات: } \\
\hline$\%$ \%Q.1 & $\%$ \%Q.1 & \%Tr.F & | محصول الف \\
\hline \%Fr.F & $\% 41.1$ & $\%$ FY.F & | محصول ب \\
\hline$\%$ \% 9.9 & $\% \mu \cdot \mathrm{r} \cdot \Delta$ & $\% \cdot r \cdot \varphi$ & | محصول ج \\
\hline \multirow[t]{2}{*}{$\%$ \% } & $\%$ \% १.१ & $\%$ \%.. & |حاشيه ناخالص (ميانگَين وزنى) \\
\hline & & \multicolumn{2}{|c|}{ فروش براى ماه قبل و یس از هايان دوره: } \\
\hline$|f, \wedge f f,| \cdot \mid$ & $\mid f, q \uparrow \Delta, r \cdot q$ & $\mid f, \wedge \Delta T, r Y G$ & 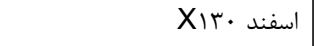 \\
\hline$|F, \wedge q|, \mid r T$ & $\mid f, \wedge 91,991$ & $|f, \wedge \vee|, V r v$ & 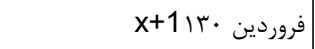 \\
\hline 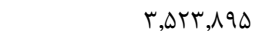 & $r, \not r r, \Lambda \cdot r$ & 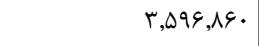 & |برگشت از فروش و تخفيفات \\
\hline$\% \cdot \cdot \cdot 1$ & $\% \cdot r \cdot V$ & $\% .+\cdot \varphi$ & ببه عنوان درصدى از فروش خالص \\
\hline$r q \wedge, \Lambda)$. & r.१,७१५ & $r \cdot \Delta, r q r$ & X اسفند • XIY \\
\hline 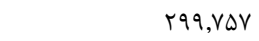 & $r \cdot 9,191$ & $r \cdot 9,191$ & |فروردين ·r+1| \\
\hline
\end{tabular}

\section{بر رسى تحليلى مربوط به هزينههاى فروش}

\begin{tabular}{|c|c|c|c|c|c|c|}
\hline \multicolumn{2}{|c|}{ حسابرسى شده دو سال قبل } & \multicolumn{2}{|c|}{ حسابرسى شده سال قبل } & \multicolumn{2}{|c|}{ سال جارى حسابرسى نشده } & \\
\hline \% فروش خالص & مقدار (ريال) & \% فروش خالص & مقدار (ريال) & \% فروش خالص & مقدار (ريال) & \\
\hline & & & & & & هزينه هاى فروش: \\
\hline$\% 1.0$ & $r, V \backslash F, \xi T \Delta$ & $\% 1.0$ & $r, 9 \wedge 1,99 \wedge$ & $\% 1.9$ & $r, Y \backslash \vee, \& \vee \Delta$ & لمزينه ضمانت نامه \\
\hline$\% \cdot \Delta$ & $\Lambda r q, 1 \uparrow \varepsilon$ & $\% \cdot \Delta$ & $\lambda F \Delta, r \vee F$ & $\% \cdot \Delta$ & AIV,rTa & هزينه مطالبات غير قابل وصول \\
\hline$\% 1 . r$ & $r, \cdot \wedge \Delta, \Delta F F$ & $\% 1 . T$ & $r, \cdot v \cdot, \cdot 11$ & $\% 1 . T$ & $r, \cdot r T, r \wedge r$ & تجبليغات \\
\hline
\end{tabular}




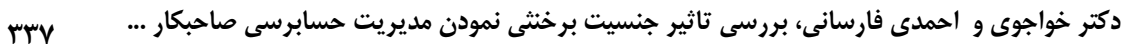

\begin{tabular}{|c|c|c|c|c|c|c|}
\hline$\%$ \%.ی & $9,491,11 \mathrm{~V}$ & $\% . \mu$ & $4,49 \vee, \wedge 9 \mathrm{D}$ & $\%$ r.v & $4,4 r \Lambda, 1 r \varepsilon$ & لحقوق و مزاياى فروش \\
\hline$\%$ \%.r & $\Delta, \vee \wedge \vee, \cdot 9 \cdot$ & $\%$ & $0, \vee ৭ 9, \vee \sim \vee$ & $\% . r . r$ & $\Delta, \mathrm{V} \varphi, \cdot \Delta \mathrm{V}$ & كميسيون فروش \\
\hline$\% \cdot . r$ & $|\Lambda, \cdot \wedge \vee, \Delta| \Psi$ & $\% 1 \cdot r$ & $1 \wedge, \cdot G 4, \xi \wedge \varphi$ & $\% \cdot .1$ & $\mid V, V T I, F \wedge \varepsilon$ & لجمع هزينههاى فروش \\
\hline$\% \cdot r \cdot \Lambda$ & $r \varepsilon, r \Delta V, I \Delta T$ & $\% \cdot r \cdot 1$ & rq, rVq, IIr & $\% \cdot r \cdot \Delta$ & $r \Delta, \wedge r r, 19 q$ & جمع هزينههاى ادارى و فروش \\
\hline
\end{tabular}

بررسى تحليلى مربوط به هزينههاى ادارى

\begin{tabular}{|c|c|c|c|c|c|c|}
\hline \multicolumn{2}{|c|}{ حسابرسى شده دو سال قبل } & \multicolumn{2}{|c|}{ حسابرسى شده سال قبل } & \multicolumn{2}{|c|}{ سال جارى حسابر سى نشده } & \\
\hline \multirow{2}{*}{ 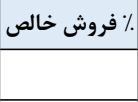 } & \multirow{2}{*}{ مقدار (ريال) } & \multirow{2}{*}{ ٪ فروش خالص } & \multirow{2}{*}{ مقدار (ريال) } & \% فروش خالص & |مقدار (ريال) & \\
\hline & & & & \multicolumn{3}{|r|}{ تز ينههاى عمومى و ادارى: } \\
\hline$\% . r .1$ & $f, q \uparrow q, q \vee ।$ & $\% . \uparrow . \Lambda$ & $F, 9 \Delta \xi, Y T r$ & $\% . r .9$ & $4,999, \uparrow \& \Delta$ & جاره \\
\hline$\% \cdot \Delta$ & $\Lambda \cdot \vee, \wedge \wedge \wedge$ & $\% \cdot \Delta$ & N.G,YTY & $\% \cdot r$ & $11 \cdot, r 91$ & ستهلاك دارايىهاى ثابت \\
\hline$\% \cdot 1$ & $|r V, \Delta| \Lambda$ & $\% \cdot 1$ & $|T V, D| \Lambda$ & $\% \cdot r$ & $|r V, \Delta| \Lambda$ & ستهلاك دارايى هاى نامشهود \\
\hline$\% \cdot .1$ & Tfr,gqV & $\% \cdot .1$ & $r r V, r \cdot \Lambda$ & $\% \cdot 1$ & $r r \Lambda, \Delta q \Lambda$ & لمن \\
\hline$\% \cdot r$ & rYG,AVT & $\% \cdot r$ & rru,qץr & $\% \cdot r$ & $r r \Delta, F \cdot F$ & عمير و نكَهدارى \\
\hline$\% \cdot \cdot$ & $4 \cdot$, fVr & $\% \cdot$ & $q \cdot, f V \cdot$ & $\% \cdot \cdot$ & $G \cdot, r \wedge \mid$ & كاز و نفت \\
\hline$\% \cdot r$ & $\{\& \wedge, q Y\}$ & $\% \cdot r$ & FE4,.9T & $\% \cdot r$ & $F \Delta F, G \cdot r$ & حدمات رفاهى \\
\hline$\% \cdot .1$ & $|r|, \Lambda \mid S$ & $\% \cdot .1$ & $r T \Delta, \cdot V F$ & $\% \cdot .1$ & TYK,QDQ & كزينه ملزومات \\
\hline$\% \cdot .9$ & $1, \cdot I V, Y \cdot V$ & $\% \cdot .9$ & $1, \cdot \Gamma \varepsilon, 1 \Gamma \Delta$ & $\% \cdot .9$ & $1, \cdot 4 \cdot, r q^{\prime}$ & يمه \\
\hline$\% 4.9$ & $\Lambda, \uparrow q \cdot, q Y F$ & $\%$ & $1, \Delta 1 \cdot, 991$ & $\% \uparrow . v$ & $\Lambda, r \vee \cdot, 911$ & حقوق و مزاياى ادارى \\
\hline$\% \cdot .9$ & $1, \Delta \wedge F, \varphi \Delta T$ & $\% \cdot .9$ & $1, \Delta \& 1, \Delta \wedge 1$ & $\% \cdot .9$ & $1, \Delta \Delta \cdot, V T \cdot$ & كاير هزينهاى عملياتى \\
\hline$\% 1 \cdot{ }^{\mathrm{k}}$ & $11, r \& 9, \& r q$ & $\% 1 \cdot .0$ & $|\Lambda, r| f, F Y G$ & $\% 1 \cdot .4$ & $1 \wedge, 111,9 \wedge \mathrm{T}$ & يمع هزينههاى ادارى \\
\hline$\% \cdot 1$ & $r \xi, r \Delta V, I \Delta \Gamma$ & $\% \cdot 1$ & ५६, rV৭, II & $\% \cdot \pi \cdot \Delta$ & $r \Delta, \lambda r r, 19 q$ & جموع هزينههاى ادارى و فروش \\
\hline
\end{tabular}

\section{فهرست منابع}

ايمانى برندقى، محمد، كاظمى علوم، مهلى؛ عبدى، مصطفى. (YY II)، بررسى تاثير تنوع جنسيتى در هيئت مديره بر احتمال وجود ضعف در كنترلهاى داخلى، دو فصلنامه

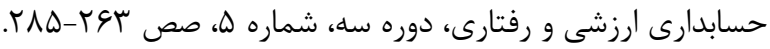

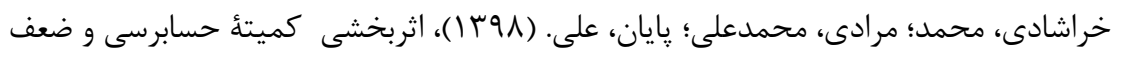

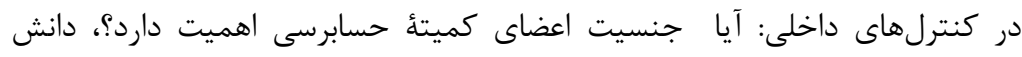

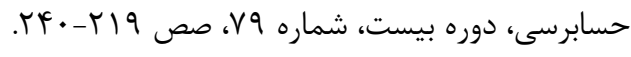

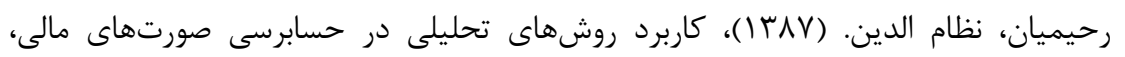

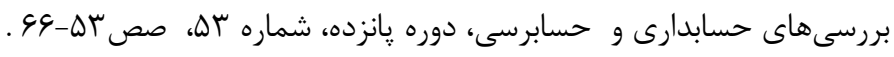

شهرابى، شاهرخ. (بو (I)، تاثير عامل جنسيت بر قضاوت حرفهاى حسابرسان داخلى، فصلنامه

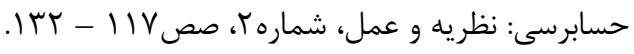




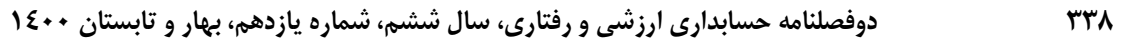

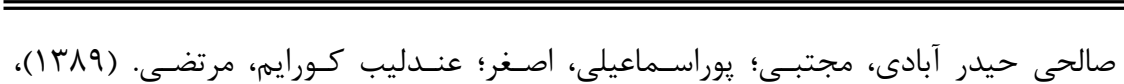

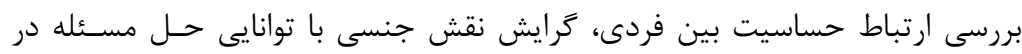

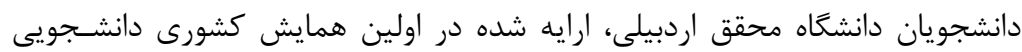

$$
\begin{aligned}
& \text { عوامل اجتماعى مؤثر بر سلامت. }
\end{aligned}
$$

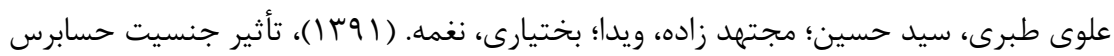

$$
\begin{aligned}
& \text { بر كيفيت حسابرسى مستقل، يزوهشهاى حسابدارى مالى و حسابرسى، دوره جهار، }
\end{aligned}
$$

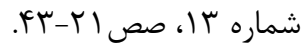

$$
\begin{aligned}
& \text { فرج زاده دهكردى، حسن. (1) (1)، رابطه ويزگى هاى شخصيتى و جنسيت با قضاوت اخلاقى }
\end{aligned}
$$

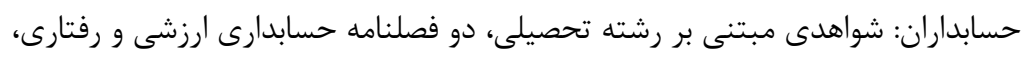

$$
\begin{aligned}
& \text { دوره جهار، شماره V، صص }
\end{aligned}
$$

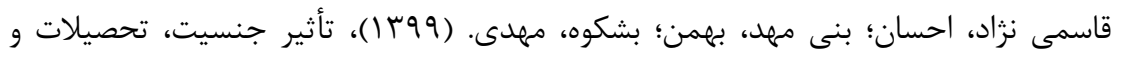

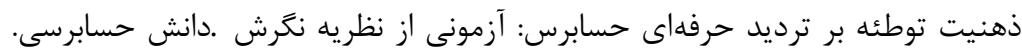

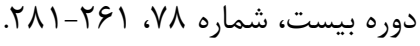

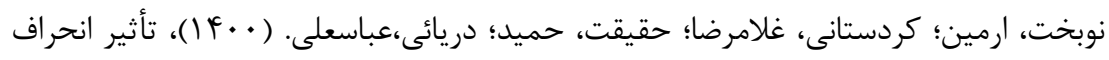

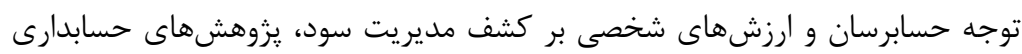

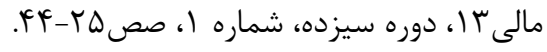

Abad, D., M. E. Lucas-PérezMinguez, A,Vera, and J.Yagüe, 2017. Does gender diversity on corporate boards reduce information asymmetry in equity markets?.BRQ Business Research Quarterly,20(3): 192-205.

Amerongen, Niels van Nieuw, 2007, The use of Business Risk Audit Risk Perspectives by Non big4 Audit Firms, Presented at the 6thEARNet Symposium Hosted by Norwegian School of Economics (NHH): 1617.

Batal. T. H., P, chand and M,lu.(2021). Influence of auditor's gender,

experience, rule observance attitudes and critical thinking disposition on materiality judgements. Internatonal journal of auditing.volume 25,hssue 1: 188- 205

Bierstaker, J. L. and S, Wright, 2001, A Research Note Concerning Practical Problem-Solving Ability as a Predictor of Performance in Auditing Tasks, Behavioral Research in A ccounting, 13 : 49-62

Bowlin, K. O.,J.L, Hobson, and M.D, Piercey, 2014. The effects of auditor rotation, professional skepticism, and interactions with managers on audit quality. Working paper, University of Mississippi, University of 


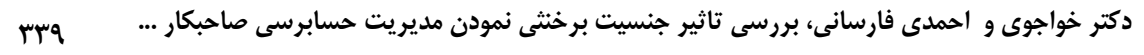

Illinois at Urbana-Champaign, and University of Massachusetts Amherst.

Early, C.E., 2002, The Differential Use of Information by Experienced \& Novice Auditors in the Performance of I11-Structured Audit Tasks, Contemporary Accounting Research ,19(4),PP. 595-614

Hao, J., V. Pham, and M. Guo, 2021. The Gender Effects of Audit Partners on Audit Outcomes: Evidence of Rule 3211 Adoption. Journal of Bussiness Ethics: $30-1$.

Hardies, K. and D. Breesch, and J. Branson, 2009, Are Female Auditors still women: Analyzing the gender differences affecting audit quality, Presented at the Mid-Atlantic region meeting of the American Accounting Association, Long Branch, NJ .

Jamal, K., P.E. Johnson, and R.G. Berryman, 1995. Detecting framingeffects in financial statements. Contemporary Accounting Research, 12 (1): $85-105$

Josep Garcia,B., M.Josep Argilés and R. Bosch Diego . 2019. Is there a gender effect on the quality of audit services? Journal of Business Research. volume98: 238-249

Knechel, R.W., 2000, Behavioral Research in Auditing \& Its Impact on Audit Education, Issues in Accounting Education, 15(4): 695-712.

Kuhn, G., B.W. Tatler , J.M.Findlay and G.G. Cole, 2008. Misdirection in magic: Implications for the relationship between eye gaze and attention. Visual Cognition, 16 (2-3): 391-405.

Madan, C. R., and M.K. Spetch, 2012. Is the enhancement on memory due to reward driven by value or salience? Acta Psychologica, 139 (2): $343-$ 349

Luippold, B. L., Kida, T., M.D. Piercey and J.F. Smith, 2015. Managing Audits to Manage Earnings: The Impact of Diversions on an Auditor's Detection of Earnings Management. Accounting, Organizations and Society, 41: 39-54.

Messier, W. F., C.A. Simon. And J.L. Smith,2013. Two decades ofbehavioral research on analytical procedures: What have we learned? Auditing: A Journal of Practice \& Theory, 32 (1): 139-181.

Moreno, K. K.,S. Bhattacharjee and D.M. Brandon, 2007.The effectiveness of alternative training techniques on analytical procedures performance. Contemporary Accounting Research, 24 (3): 983-1014

Moore, D.A.,P.E.Tetlock, L.Tanlu and M.H. Bazerman , 2006, Conflicts of Interest \& the Case of Auditor Independence: Moral Seduction \& Strategic Issue Cycling, Academy of Management Review, 31(1): 1029.

Niskanen, M., J. Niskanenand, J. Karjalainen and J. Karjalainen, 201 ', Auditor Gender \& Corporate Earning Management Behaviourin 
Private Finnish Firms, Presented at the 33rdAnnual Congress of the European Accounting Association, May 19-21, Istanbul.

O'Donnell, E., and E.N. Johnson, 2001, The Effects of Auditor Processing Efficiency, International Journal of Auditing, 5(2): 91-105.

Sagarin, B. J., M.A. Britt, J.D. Heider, S.E. Wood, and J.E. Lynch,2003. Bartering our attention: The distraction and persuasion effects of online advertisements. Cognitive Technology, 8: 4-17

Reskin, B.F and D, Bielby, 2005. A sociological perspective on gender and career outcomes. Journal of Economic Perspectives 19 (1): 71-86.

Smith, S. D.,W.B. Tayler, and D.F. Prawitt, 2011. The effect of information pursuit on judgments and confidence of auditors. Working paper, Brigham Young University.

Tan, H.T., and A. Kao, 1999, Accountability Effects on Auditor's Performance : The Influence of Knowledge, Problem-Solving Ability, \& Task Complexity, Journal of Accounting Research, 37(1): 209-223. 